\title{
Genome Sequencing and Transcriptome Analysis of the Hop Downy Mildew Pathogen Pseudoperonospora humuli Reveal Species-Specific Genes for Molecular Detection
}

\author{
A. Rahman, ${ }^{1}$ E. Góngora-Castillo, ${ }^{1,2}$ M. J. Bowman, ${ }^{3}$ K. L. Childs, ${ }^{3}$ D. H. Gent, ${ }^{4}$ F. N. Martin, ${ }^{5}$ \\ and L. M. Quesada-Ocampo ${ }^{1, \dagger}$ \\ ${ }^{1}$ Department of Entomology and Plant Pathology, North Carolina State University, Raleigh, NC 27695-7613, U.S.A. \\ ${ }^{2}$ Department of Biotechnology, Yucatan Center for Scientific Research, 97205 Mérida, Yucatán, México \\ ${ }^{3}$ Department of Plant Biology, Michigan State University, East Lansing, MI 48823, U.S.A. \\ ${ }^{4}$ Forage Seed and Cereal Research Unit, U.S. Department of Agriculture-Agricultural Research Service and Oregon State University, Corvallis \\ 97331, OR, U.S.A. \\ ${ }^{5}$ Crop Improvement and Protection Research Station, U.S. Department of Agriculture-Agricultural Research Service, Salinas, CA 93905, \\ U.S.A. \\ Accepted for publication 26 March 2019.
}

\begin{abstract}
Pseudoperonospora humuli is an obligate oomycete pathogen of hop (Humulus lupulus) that causes downy mildew, an important disease in most production regions in the Northern Hemisphere. The pathogen can cause a systemic infection in hop, overwinter in the root system, and infect propagation material. Substantial yield loss may occur owing to $P$. humuli infection of strobiles (seed cones), shoots, and cone-bearing branches. Fungicide application and cultural practices are the primary methods to manage hop downy mildew. However, effective, sustainable, and cost-effective management of downy mildew can be improved by developing early detection systems to inform on disease risk and timely fungicide application. However, no species-specific diagnostic assays or genomic resources are available for $P$. humuli. The genome of the $P$. humuli OR502AA isolate was partially sequenced using Illumina technology and assembled with ABySS. The assembly had a minimum scaffold length of $500 \mathrm{bp}$ and an N50 (median scaffold length of the

assembled genome) of $19.2 \mathrm{kbp}$. A total number of 18,656 genes were identified using MAKER standard gene predictions. Additionally, transcriptome assemblies were generated using RNA-seq and Trinity for seven additional $P$. humuli isolates. Bioinformatics analyses of next generation sequencing reads of $P$. humuli and $P$. cubensis (a closely related sister species) identified 242 candidate species-specific $P$. humuli genes that could be used as diagnostic molecular markers. These candidate genes were validated using polymerase chain reaction against a diverse collection of isolates from P. humuli, P. cubensis, and other oomycetes. Overall, four diagnostic markers were found to be uniquely present in $P$. humuli. These candidate markers identified through comparative genomics can be used for pathogen diagnostics in propagation material, such as rhizomes and vegetative cuttings, or adapted for biosurveillance of airborne sporangia, an important source of inoculum in hop downy mildew epidemics.
\end{abstract}

Hop (Humulus lupulus) is an herbaceous and diocecious perennial crop mainly grown to produce beer and ale (Natsume et al. 2015; Neve 1991). During spring, shoots emerge from rhizomes or crowns and grow along a vertical trellis system (Chee et al. 2006; Neve 1991). Flowering begins in the summer on lateral branches, and female plants produce cones that provide the bitterness and hop aroma to beer and ale. This is owing to lupulin glands in cones that produce resins and essential oils, such as alpha and beta acids (Natsume et al. 2015). In the United States, most of the hop acreage is in Washington, Oregon, and Idaho, which comprise $\sim 23 \%$ of the world's total acreage (MacKinnon 2004). Hop downy mildew, caused

${ }^{\dagger}$ Corresponding author: L. M. Quesada-Ocampo; lmquesad@ncsu.edu

Funding: This work was supported by U.S. Department of Agriculture Animal and Plant Health Inspection Service (USDA-APHIS) award 15-8130-0274 and the U.S. Department of Agriculture-Agricultural Research Service under projects NC02628 (to L. M. Quesada-Ocampo) and CRIS 2072-21000-046-00 (to L. M. QuesadaOcampo). This work was also partially supported by U.S. National Science Foundation grant IOS-1126998 (to K. L. Childs).

A. Rahman and E. Góngora-Castillo contributed equally to this work.

*The $\boldsymbol{e}$-Xtra logo stands for "electronic extra" and indicates that four supplementary figures, four supplementary files, and one supplementary table are published online.

The author(s) declare no conflict of interest.

(C) 2019 The American Phytopathological Society by Pseudoperonospora humuli, is the number one threat to hop production in wet production regions owing to widespread fungicide resistance in the pathogen populations and lack of disease resistance in most hop cultivars (Coley-Smith 1964; Gent and Ocamb 2009; Gent et al. 2008). This biotrophic oomycete can infect hop crowns systemically, which allows overwintering as mycelia and results in infected shoots in the following spring referred to as basal spikes (Coley-Smith 1962). The pathogen can be disseminated in systemically infected planting material: both rhizomes and plants produced from softwood cuttings (Royle and Kremheller 1981). Sporangiophores bearing sporangia are produced on infected tissue and spread via wind and water splashing to new foliage and cones when environmental conditions are favorable (Gent and Ocamb 2009). Oospores, thick-walled resting spores produced in infected tissue, may play a role in overwintering, but their importance in epidemic development is believed to be minor because of their low rates of germination (Coley-Smith 1962; Gent et al. 2017).

Hop is just one of many crops severely affected by downy mildew diseases. Several downy mildew pathogens have emerged or reemerged and caused devastating damage in food and ornamental crops, such as cucumber (Pseudoperonospora cubensis) (Holmes et al. 2015; Ojiambo et al. 2015; Savory et al. 2011), basil (Peronospora belbahrii) (Wyenandt et al. 2015), rudbeckia (Plasmopara halstedii) (Rivera et al. 2016), and impatiens (Plasmopara obducens) (Palmateer et al. 2013). Other downy mildew pathogens have been established in the United States for many years, but although 
these pathogens are economically important and taxonomically diverse (Thines 2014; Thines and Choi 2016), they remain largely understudied in part because of the inherent difficulty of working with obligate parasites (Guo et al. 2016). The first downy mildew pathogen genome to be sequenced was Hyaloperonospora arabidopsidis (Baxter et al. 2010), the Arabidopsis thaliana downy mildew, and since then, other draft and higher-quality genomes have been published for P. cubensis (cucurbit downy mildew) (Savory et al. 2012), Plasmopara halstedii (sunflower downy mildew) (Sharma et al. 2015), Peronospora tabacina (tobacco downy mildew) (Derevnina et al. 2015), and Plasmopara viticola (grape downy mildew) (Dussert et al. 2016). However, regardless of the expansion of genomics resources for some downy mildew pathogens, connecting genotypes to phenotypes and development of markers for population studies or pathogen diagnostics have not increased at the same rate (Crandall et al. 2018; Wallace and Quesada-Ocampo 2017; Withers et al. 2016).

In the field, downy mildew is typically diagnosed by visual examination of foliar tissue that will display typical disease lesions and in many cases, pathogen sporulation (Fig. 1) (Holmes et al. 2015). Because secondary inoculum from sporulating foliage is critical for downy mildew epidemics, many diagnostic efforts have focused on detection of airborne sporangia by using spore traps

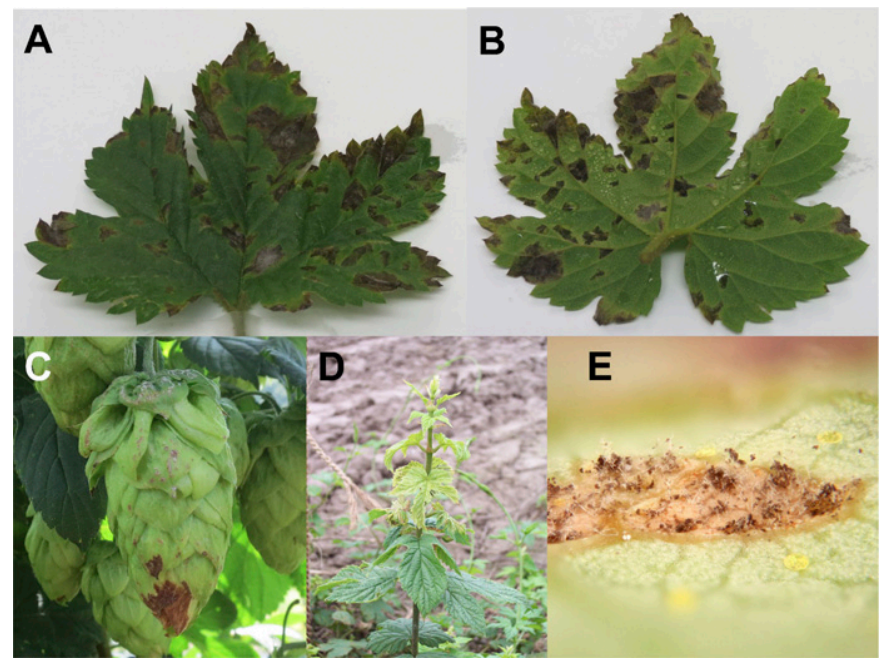

Fig. 1. Downy mildew symptoms on hop caused by Pseudoperonospora humuli. A, Foliar infection with characteristic angular lesions delimited by leaf veins. B, Profuse pathogen sporulation on the underside of the leaf. $\mathbf{C}$, Cone infection with irregular necrotic lesions. D, Chlorotic and stunted shoots or spikes of hop with a systemic infection of $P$. humuli. E, Sporangiophores with sporangia on the underside of the leaf at $20 \times$ magnification (courtesy of Matthew Bertone).
(Gent et al. 2009; Klosterman et al. 2014; Kong et al. 2016; Kunjeti et al. 2016). Diagnostic assays available for downy mildew pathogens are mostly based on detection of the internal transcribed spacer (ITS), which may cross-detect closely related species on a mixed sample (Gent et al. 2009; Klosterman et al. 2014). Nonetheless, many downy mildew pathogens are systemic or seedborne, such as is the case with hop, sunflower, and basil downy mildew, and a combination of serological and molecular diagnostics with robust survey mechanisms is desirable for pathogen detection before planting or before foliar symptoms appear (Roeckel-Drevet et al. 1999; Wyenandt et al. 2015). To address this need, in this study, we used a comparative genomics strategy to identify species-specific markers for detection of $P$. humuli. Specifically, we aimed to (i) generate a draft genome assembly of $P$. humuli; (ii) use the published draft genome of $P$. cubensis, the causal agent of cucurbit downy mildew and sister species of $P$. humuli, to identify $P$. humuli species-specific genes; and (iii) evaluate the putative identified species-specific genes as diagnostic markers for the pathogen.

\section{MATERIALS AND METHODS}

Pathogen material, DNA and RNA extraction, library preparation, and sequencing of $\boldsymbol{P}$. humuli. $P$. humuli isolate OR502AA was propagated in detached hop leaves of cultivar Pacific Gem to generate sporangia for DNA extraction and used for genome sequencing as previously described (Withers et al. 2016). Isolate OR502AA and seven other $P$. humuli isolates were also propagated for RNA extraction and sequencing following the same procedure (Table 1). Transcriptome sequencing data from eight $P$. humuli and seven $P$. cubensis isolates published in Withers et al. (2016) were used in this study for the comparative analysis as described below (GenBank BioProject accession number PRJNA293744). For next generation sequencing (NGS), DNA and RNA were extracted from $50 \mu \mathrm{l}$ of sporangial suspensions of each isolate as described previously (Withers et al. 2016), whereas 2 to $3 \mathrm{~mm}$ infected and uninfected leaf tissue segments were used to extract DNA for primer validation using a phenol-chloroform DNA extraction method (Withers et al. 2016), resuspended in 30 to $100 \mu \mathrm{l}$ of distilled water, and quantified using a Nanodrop 1000 (Thermo Fisher Scientific) according to the manufacturer's instructions. $P$. humuli DNA samples not previously sequenced by Withers et al. (2016) were submitted to The Genomic Science Laboratory at North Carolina State University for library preparation and sequencing in an Illumina NextSeq 500 (Illumina Inc.). Two different insert size DNA libraries ( 350 and $800 \mathrm{bp}$ ) were pair end sequenced at a read length of 100 nucleotides for $P$. humuli OR502AA. The predicted coding genes from $P$. cubensis isolate

TABLE 1. Pseudoperonospora humuli and P. cubensis isolates used for Illumina RNA and DNA sequencing

\begin{tabular}{|c|c|c|c|c|c|c|c|c|}
\hline $\begin{array}{l}\text { Pathogen } \\
\text { species }\end{array}$ & Isolate & Host & Location & Year collected & Source & $\begin{array}{l}\text { Sequenced } \\
\text { molecule }\end{array}$ & $\begin{array}{l}\text { Sequencing } \\
\text { type }\end{array}$ & Read length \\
\hline P. humuli & NY482CA & Humulus lupulus (hop) & New York & 2011 & Gent & RNA & Single end & 50 \\
\hline P. humuli & JP490-5 & Humulus lupulus (hop) & Aomori, Japan & 2012 & Gent & RNA & Single end & 50 \\
\hline P. humuli & JP490 & Humulus lupulus (hop) & Aomori, Japan & 2012 & Gent & RNA & Single end & 50 \\
\hline P. humuli & JP498SA & Humulus lupulus (hop) & Ehoro, Japan & 2012 & Gent & RNA & Single end & 50 \\
\hline P. humuli & OR501BA & Humulus lupulus (hop) & Oregon & 2013 & Gent & RNA & Single end & 50 \\
\hline P. humuli & OR502AA & Humulus lupulus (hop) & Oregon & 2013 & Gent & $\begin{array}{l}\text { RNA } \\
\text { and DNA }\end{array}$ & $\begin{array}{l}\text { Single end and } \\
\text { paired end }\end{array}$ & $\begin{array}{l}50 \\
\text { and } 100\end{array}$ \\
\hline P. humuli & VT503A3 & Humulus lupulus (hop) & Virginia & 2013 & Gent & RNA & Single end & 50 \\
\hline P. humuli & WI510-1 & Humulus lupulus (hop) & Wisconsin & 2013 & Gent & RNA & Single end & 50 \\
\hline P. cubensis & CA08A1 & Cucumis sativus (cucumber) & California & 2008 & Ojiambo & RNA & Single end & 50 \\
\hline P. cubensis & SC1982 & Cucumis melo (cantaloupe) & South Carolina & 1982 & Ojiambo & RNA & Single end & 50 \\
\hline P. cubensis & NC2013C3 & Cucurbita maxima (pumpkin) & North Carolina & 2013 & Ojiambo & RNA & Single end & 50 \\
\hline P. cubensis & SC2013F2 & Cucurbita pepo (acorn squash) & South Carolina & 2013 & Ojiambo & RNA & Single end & 50 \\
\hline P. cubensis & NCA11 & Cucumis sativus (cucumber) & North Carolina & 2012 & Ojiambo & RNA & Single end & 50 \\
\hline P. cubensis & SCD3 & Cucurbita moschata (butternut squash) & South Carolina & 2012 & Ojiambo & RNA & Single end & 50 \\
\hline P. cubensis & NCWAY2-1 & Cucumis sativus (cucumber) & North Carolina & 2013 & Quesada & RNA & Single end & 50 \\
\hline
\end{tabular}


MSU1 (GenBank accession number SRX025566.1) reported by Savory et al. (2012) were used for comparative sequence analysis with $P$. humuli OR502AA. Reads generated in this study can be found under BioProject accession number PRJNA354153.

Genome assembly and annotation of the $P$. humuli nuclear genome. HiSeq Illumina 100-bp paired end reads of $P$. humuli OR502AA genomic DNA (all samples were run on an Illumina HiSeq 2500; Illumina Inc.) were analyzed for quality using FastQC version 0.10.1 (Andrews 2012), Cutadapt version 1.8.1 (Martin 2012), and FASTX toolkit version 0.0.13 (Hannon 2010). A preliminary genome assembly of $P$. humuli OR502AA was performed with ABySS version 1.5.2 (Simpson et al. 2009) using a $k$-mer of 71 in paired end library mode. The preliminary assembly was inspected using Blobology for bacterial, plant, and other contamination expected when sequencing an obligate pathogen (Kumar et al. 2013). Results were plotted using the ggplot2 package from $\mathrm{R}$ version 3.2.4 (R Core Team 2017; Wickham 2009) (Supplementary Fig. S1). After removing reads associated with contamination microorganisms and host plant, a new ABySS genome assembly was generated with a minimum scaffold length of $500 \mathrm{bp}$; then, gene structural predictions were generated with the MAKER structural annotation pipeline (Cantarel et al. 2008; Holt and Yandell 2011). Transcriptome assemblies of $P$. humuli OR502AA and seven additional isolates of $P$. humuli were used as transcript evidence (Tables 1 and 2). Assemblies were generated using Trinity (version 2014) with a minimum contig length of $150 \mathrm{bp}$ and the Jaccard clip option (Haas et al. 2013). The completeness of the genome assembly was assessed based on the percentage of coverage of 248 core eukaryotic genes from CEGMA version 2.5 (Parra et al. 2007) (Table 3) and a database of 429 eukaryote groups from BUSCO version 1.1 (Simão et al. 2015). Predicted proteins were functionally annotated using BLASTP searches to NCBI NR database (e value 1e-05; version March 2017), and Uniprot, InterPro, Pfam motifs, and Gene Ontology (GO) terms were assigned by cross-reference using Retrieve ID/Mapping Uniprot tools (The UniProt Consortium 2018) (Supplementary File S1). The $P$. humuli genome length was also estimated through GenomeScope (Vurture et al. 2017) by using DNA-seq read length and $k$-mer profile analyses with Jellyfish (Marçais and Kingsford 2011). The nuclear genome assembly and annotation of $P$. humuli OR502AA can be found under GenBank accession number PRJNA354153 and in figshare (https:// figshare.com/s/5cfeda89bd3d29f3d259 and https://figshare.com/s/ $35951 \mathrm{fc} 4569554 \mathrm{efdc} 34$, respectively).

Genome assembly and annotation of the $P$. humuli mitochondrial genome. Illumina raw reads of $P$. humuli isolate OR502AA obtained in this study were used for mitochondrial genome assembly. A de novo assembly was done in SeqMan NGen version 4.1.2 (DNASTAR), and the resulting contigs were screened for mitochondrial genes by BLAST analysis (Altschul et al. 1990) with the mitochondrial genome of Phytophthora ramorum (accession

TABLE 2. Transcriptome assemblies statistics of Pseudoperonospora humuli isolates

\begin{tabular}{lccrc}
\hline $\begin{array}{l}\text { Isolate } \\
\text { identification }\end{array}$ & $\begin{array}{c}\text { Number of } \\
\text { contigs }\end{array}$ & $\begin{array}{c}\text { N50 } \\
\text { median contig } \\
\text { length (bp) }\end{array}$ & $\begin{array}{c}\text { Longest } \\
\text { contig } \\
\text { length (bp) }\end{array}$ & $\begin{array}{c}\text { Shortest } \\
\text { contig } \\
\text { length (bp) }\end{array}$ \\
\hline OR502AA & 42,862 & 2,051 & 10,982 & 151 \\
JP498SA & 31,655 & 735 & 6,454 & 151 \\
WI510-1 & 26,677 & 456 & 4,348 & 151 \\
OR501BA & 19,116 & 419 & 3,909 & 151 \\
VT503A3 & 22,185 & 423 & 5,153 & 151 \\
NY481J1 & 42,048 & 1,390 & 7,114 & 151 \\
NY482CA & 21,919 & 473 & 10,772 & 151 \\
JP490 & 15,842 & 322 & 3,846 & 151 \\
JP490-5 & 27,310 & 599 & 10,772 & 151 \\
NY507570bc & 46,600 & 1,660 & 9,306 & 151 \\
NC18668CAS & 67,248 & 2,013 & 22,752 & 151 \\
NC18668GAL & 108,802 & 635 & 8,147 & 151 \\
\hline
\end{tabular}

number DQ832718) and Peronospora tabacina (accession number KT893455). Mitochondrial contigs were reassembled using the small template assembly option of SeqMan NGen to extend the ends of the contigs and close gaps. Coverage in the assembly was screened manually, and contigs were broken when gaps, low coverage, or inconsistencies were observed and then, reassembled. This iterative process was repeated until the entire mitochondrial genome was assembled. Open reading frames (ORFs) were predicted and annotated with DS Gene version 1.5 (Accelrys) using the universal genetic code with confirmation of gene identities using BLAST analysis against the published mitochondrial genome sequences noted above. Transfer RNA (tRNA) coding regions were placed using tRNAscan-SE version 1.3.1 (Lowe and Eddy 1997). The mitochondrial genome assembly and annotation of $P$. humuli OR502AA can be found under GenBank accession number MH923236 and in figshare at https://figshare.com/s/ $61 \mathrm{f} 5 \mathrm{dc} 6091 \mathrm{c} 0271114 \mathrm{e} 4$. Gene order comparisons with other oomycete mitochondrial genomes (Achlya hypogyna, KF226724; Phytophthora ramorum, DQ832718; Phytophthora sojae, DQ832718; Phytophthora infestans, NC002387; Phytophthora nicotianae, KY85130; Phytophthora poloncia, KT946598; Peronospora tabacina, KT893455; Pythium ultimum, GU138662; Pythium insidiosum, AP014838; P. cubensis, KT072718; and Saprolegnia ferax, AY534144) were done manually by aligning annotated genomes.

Identification of putative RXLR-like and CRN effector proteins. Putative RXLR, RXLR-like, and CRN effector proteins were identified using the effect" and ShinyR packages of R version 3.4.4 and customized Perl scripts (R Core Team 2017). After identification, each effector protein was checked manually for the presence of the corresponding motif. For predictions of signal peptide presence, SignalP version 4.0 in "sensitive" mode was used for all putative effector proteins (Petersen et al. 2011).

Bioinformatics analyses for identification of diagnostic markers. RNA sequencing reads from $P$. humuli and $P$. cubensis were analyzed for quality using FastQC version 0.10.1 (Andrews 2012), Cutadapt version 1.8.1 (Martin 2012), and FASTX toolkit version 0.0.13 (Hannon 2010) as described in Withers et al. (2016). When sequencing an obligate pathogen, it is expected to obtain a mix of host and pathogen sequences as well as a large quantity of phyllosphere microbiome. Thus, to determine the level of host contamination in pathogen sequences, an H. lupulus var. lupulus (common hop or hop) genome sequence was downloaded from NCBI under GenBank accession number BBPC00000000.1 (Natsume et al. 2015), and RNA-seq reads were aligned using Bowtie2 version 2.1.0 (Langmead and Salzberg 2012) (Table 4). To identify species-specific diagnostic markers, RNA sequencing reads from $P$. humuli and $P$. cubensis were aligned to the $P$. humuli genome assembly generated in this study and the published P. cubensis draft genome (Savory et al. 2012) using Bowtie2 version 2.1.0 with default "valid" alignment mode (Langmead and Salzberg 2012). The number of aligned reads for each exon of the $P$. humuli genome assembly was quantified using htseq-count from HTSeq version 0.6.1 (Anders et al. 2015) in "union" mode and normalized using Quantile Normalization with R (Bolstad et al.

TABLE 3. Genome assembly statistics of Pseudoperonospora humuli

\begin{tabular}{lr}
\hline Number of scaffolds & 5,534 \\
Total size of scaffolds (bp) & $40,506,691$ \\
Longest scaffold (bp) & 195,040 \\
Number of scaffolds $>1,000$ & 4,511 \\
Number of scaffolds $>10,000$ & 1,026 \\
Number of scaffolds $>100,000$ & 12 \\
N50 median scaffold length (bp) & 19,165 \\
Average length of break ( $>25 \mathrm{Ns})$ between contigs & 111 \\
$\quad$ in scaffold & 0.24 \\
Scaffold (\% N) & 97.8 \\
CEGMA complete $(\%)$ & 98.8 \\
CEGMA cartial $(\%)$ & \\
\hline
\end{tabular}


2003; R Core Team 2017). A Perl script was used to identify exons in the $P$. humuli genome with at least two or more quantiles in $P$. humuli RNA samples and less than two quantiles from $P$. cubensis RNA samples. Exons present in all $P$. humuli RNA samples (two or more quantiles) but absent in all $P$. cubensis samples (less than two quantiles) were matched to specific genes using the $P$. humuli genome assembly GFF3 file coordinates (Fig. 2 and Supplementary File S2). A $\log _{2}$ transformation was used to plot $P$. humuli isolates expression values into a heatmap using "heatmap.2” from the R "gplots" package (R Core Team 2017). To determine if diagnostic markers were in single-copy genes, a self-BLAST (Altschul et al. 1990) analysis of the P. humulipredicted proteins using an e-value cutoff of $1 \mathrm{e}^{-10}$ was performed. Genes were considered single copy if protein sequences had only one match to the proteome. Because several diagnostic markers were annotated as genes of unknown function, a BLASTX analysis (e-value cutoff of $1 \mathrm{e}^{-05}$ ) against Phytophthora infestans, Phytophthora capsici, and $H$. arabidopsis proteins was performed to improve gene functional annotation.

Primer design and validation of candidate diagnostic markers. The species-specific diagnostic markers identified after bioinformatics analyses were validated by polymerase chain reaction (PCR) against a larger collection of lesions infected with P. humuli or P. cubensis, other oomycete isolates, and host plants. Fasta sequences of genes containing diagnostic markers and the 200-bp region flanking each gene were selected using extracseq from EMBOSS version 6.5.7 (Ison et al. 2011). Primers were designed within 200 bp of the $5^{\prime}$ and $3^{\prime}$ ends of each gene with a diagnostic marker using Geneious 10.2.3 (Biomatters Ltd.). Primers were designed to produce product sizes between 500 and 1,500 bp, with an annealing temperature of 55 to $58^{\circ} \mathrm{C}$, and they were ordered through Integrated DNA Technologies or Eton Bioscience, Inc. The PCR reactions, completed according to the manufacturer's guidelines, contained 1× Promega GoTaq Green Master Mix (Promega) and $10 \mu \mathrm{M}$ forward and reverse primers, and they were amplified with a program starting at $94^{\circ} \mathrm{C}$ for $3 \mathrm{~min}$ followed by 35 cycles of $94^{\circ} \mathrm{C}$ for $30 \mathrm{~s}, 55^{\circ} \mathrm{C}$ for $30 \mathrm{~s}$, and $72^{\circ} \mathrm{C}$ for $30 \mathrm{~s}$ and a final elongation step of $72^{\circ} \mathrm{C}$ for $5 \mathrm{~min}$. Products were analyzed by gel electrophoresis on a $2.0 \%$ agarose gel containing $0.2 \mu \mathrm{g} / \mathrm{ml}$ ethidium bromide followed by detection with a Bio-Rad Geldoc Imager using Quantity One software (Bio-Rad). Product sizes were estimated by comparison with a 100-bp DNA ladder (Fisher BioReagents exACTGene DNA Ladders; Fisher Scientific). Diagnostic candidates with product sizes similar in P. humuli and P. cubensis samples as well as any that were amplified in any of the plant hosts or other oomycetes screened were eliminated. Remaining diagnostic markers after validation were considered highly specific to $P$. humuli.

\section{RESULTS}

$P$. humuli genome sequencing, assembly, quality assessment, and functional annotation of predicted genes. The $P$. humuli isolate OR502AA originally collected in Oregon from the hop cultivar Centennial was sequenced using Illumina (paired end libraries) to $100 \times$ coverage. The preliminary genome assembly was inspected for bacterial contamination using Blobology tools (Kumar et al. 2013). As expected for a foliar obligate pathogen, sequenced reads corresponding to prokaryote contaminants, including Xhantomonadales, Pseudomonadales, Sphingobacteriales, Burkholderiables, Flavobacteriales, and Micrococcales, were found. After removing contaminants, a final de novo assembly was performed, resulting in 5,534 scaffolds and spanning $40.6 \mathrm{Mb}$; this correspond to 53.8 to $50.1 \%$ of the predicted genome size, which was estimated to be 75.4 to $80.9 \mathrm{Mb}$ using Feulgen Absorbance Cytophotometry by Voglmayr and Greilhuber (1998). However, genome size estimation with GenomeScope (Vurture et al. 2017) and $k$-mer profile using OR502AA DNA-seq reads (Table 4) resulted in a $P$. humuli genome length of $47.2 \mathrm{Mb}$ (Supplementary Fig. S2) (http://qb.cshl.edu/genomescope/analysis.php?code= 0p5xas2Qjku8bkgO53Nq).

An N50 (median scaffold length) of $19.2 \mathrm{~kb}$ was obtained, with the largest scaffold of $195 \mathrm{~kb}$ (Table 3 ). To further assess the quality of the assembly, BLASTN searches (Altschul et al. 1990) were performed against hop sequences, and the results showed insignificant similarity to the sequences of the host $(0.0045 \%$ similarity). CEGMA and BUSCO analyses of scaffolds indicated that the gene space of this genome is well represented in the assembly. Although CEGMA analysis indicated 97.8 and $98.9 \%$ of complete and partial core eukaryotic gene representations, respectively (Table 3), BUSCO assessment identified only $79 \%$ of core genes (Parra et al. 2007; Simão et al. 2015). Of 429 core eukaryotic genes provided by BUSCO, 341 complete single-copy BUSCOs and 66 complete duplicated BUSCOs were found in the assembled genome.

A total of 18,677 predicted genes were obtained from the transcriptomes of eight $P$. humuli isolates (Table 1), summing to a coding space size of $28.1 \mathrm{Mb}$. Of these, we found evidence of expression for 9,938 (53\%) predicted genes in at least one of the isolates. Predicted proteins from gene models were annotated using

TABLE 4. Mapping statistics of RNA-seq reads to the Pseudoperonospora humuli genome

\begin{tabular}{|c|c|c|c|c|c|c|c|}
\hline Pathogen species & Isolate & Molecule & $\begin{array}{l}\text { Sequencing } \\
\text { mode }\end{array}$ & $\begin{array}{l}\text { Number of } \\
\text { total reads }\end{array}$ & $\begin{array}{c}\text { Number of } \\
\text { high-quality reads }\end{array}$ & $\begin{array}{l}\text { Mapped reads } \\
\text { to } P \text {. humuli }(\%)\end{array}$ & $\begin{array}{c}\text { Mapped reads to } \\
\text { Humulus lupulus } \\
\text { var. lupulus } \\
\text { GCA_000831365.1 (\%) }\end{array}$ \\
\hline P. humuli & NY482CA & RNA & SE & $15,906,769$ & $15,860,532$ & 74.24 & 9.34 \\
\hline P. humuli & JP490-5 & RNA & SE & $20,211,068$ & $20,149,698$ & 83.06 & 5.18 \\
\hline P. humuli & JP490 & RNA & SE & $11,942,671$ & $11,913,949$ & 51.16 & 9.23 \\
\hline P. humuli & JP498SA & RNA & SE & $26,977,356$ & $26,866,989$ & 90.58 & 0.45 \\
\hline P. humuli & OR501BA & RNA & SE & $14,429,953$ & $14,399,612$ & 75.62 & 6.81 \\
\hline P. humuli & OR502AA & RNA & SE & $26,193,148$ & $26,086,672$ & 93.20 & 0.35 \\
\hline P. humuli & VT503A3 & RNA & SE & $14,576,962$ & $14,543,704$ & 79.01 & 6.77 \\
\hline P. humuli & WI510-1 & RNA & SE & $29,264,282$ & $29,150,378$ & 85.94 & 0.91 \\
\hline P. humuli & OR502AA_R1 ${ }^{\mathrm{a}}$ & DNA & PE1 & $36,599,100$ & $21,778,230$ & 59.40 & 0.58 \\
\hline P. humuli & OR502AA_R2a & DNA & PE2 & $36,599,100$ & $21,778,230$ & 55.68 & 0.6 \\
\hline P. cubensis & CA08A1 & RNA & $\mathrm{SE}$ & $23,691,206$ & $23,576,348$ & 87.10 & 1.69 \\
\hline P. cubensis & SC1982 & RNA & SE & $22,117,725$ & $22,049,442$ & 74.88 & 7.76 \\
\hline P. cubensis & NC2013C3 & RNA & SE & $28,035,867$ & $27,888,243$ & 81.34 & 1.92 \\
\hline P. cubensis & SC2013F2 & RNA & SE & $16,956,357$ & $16,886,934$ & 61.48 & 8.98 \\
\hline P. cubensis & NCA11 & RNA & SE & $28,101,878$ & $27,962,061$ & 81.76 & 0.62 \\
\hline P. cubensis & SCD3 & RNA & SE & $29,304,711$ & $29,218,196$ & 81.65 & 4.86 \\
\hline P. cubensis & NCWAY2-1 & RNA & SE & $21,038,800$ & $20,974,369$ & 61.48 & 7.16 \\
\hline P. cubensis & MSU1 & DNA & SE & $57,635,614$ & $1,687,221$ & 49.38 & 1.72 \\
\hline
\end{tabular}

a Paired end DNA-seq used for $P$. humuli genome assembly. SE, single end; PE, paired end. 
BLASTP search against the NR NCBI database (version March 2017), and 15,037 of these sequences had significant alignments to 10,036 unique proteins. The KAAS tool was used to identify 2,868 metabolic pathways associated with 3,772 predicted gene models (Kanehisa et al. 2016; Moriya et al. 2007). UniProt Knowledge Base (UniProtKB) annotation was successfully assigned to 14,991 predicted gene models by cross-reference using Uniprot (Retrieve/ID mapping) tools (The UniProt Consortium 2016) to identify 10,062 UniProtKB proteins; InterPro and Pfam annotations were assigned to 10,108 and 8,483 predicted gene models, respectively. GO terms were assigned to a total of 7,641 of 18,656 predicted genes. Of these, molecular function ontologies were associated with 5,737 predicted gene models, and functions related to binding (macromolecular complex binding, organic cyclic compound binding, and heterocyclic compound binding) and catalytic activity (hydrolase activity, transferase activity, and catalytic activity acting on protein) were highly represented in these genes (Fig. 3). A total of 3,295 predicted genes were associated with biological processes, and most of these genes were involved in cellular and metabolic processes, such as cellular metabolic process, cellular component organization, organic substance metabolic process, and primary metabolic process among others. Lastly, 4,150 predicted genes models were assigned ontologies from the cellular component module, and proteins associated with the membrane were highly represented (Supplementary Fig. S3).

Some proteins secreted by oomycetes are essential for a successful host infection (Birch et al. 2006; Bozkurt et al. 2012; Dodds et al. 2009). The major class of cytoplasmic effectors secreted by oomycetes pathogens is the RXLR effectors that contain a conserved RXLR motif. Searching for this motif across the genome sequence makes it feasible to identify candidate RXLR effector genes (Birch et al. 2008, 2009; Jiang et al. 2008; Morgan and Kamoun 2007; Win et al. 2012). A total of 189 putative RXLR and RXLR-like effectors were predicted from the secretome of $P$. humuli isolate OR502AA genome (Supplementary Fig. S4 and Supplementary File S3). A considerably higher number of RXLR motif effectors were identified compared with other RXLR-like effectors, such as QXLR, RXXLR, and QXXLR, in the P. humuli genome. In addition to RXLR effectors, CRN (crinkler family candidates) proteins were also identified (Table 5). A total of 49 putative CRN family proteins harboring either one or both LFLAK and HVLV motifs was found. A plethora of other family proteins involved in plant pathogenicity that have been noted in other oomycetes was also determined. The $P$. humuli genome was found to harbor a similar number of pathogenicity proteins compared with other downy mildew and oomycete pathogens (Table 5).
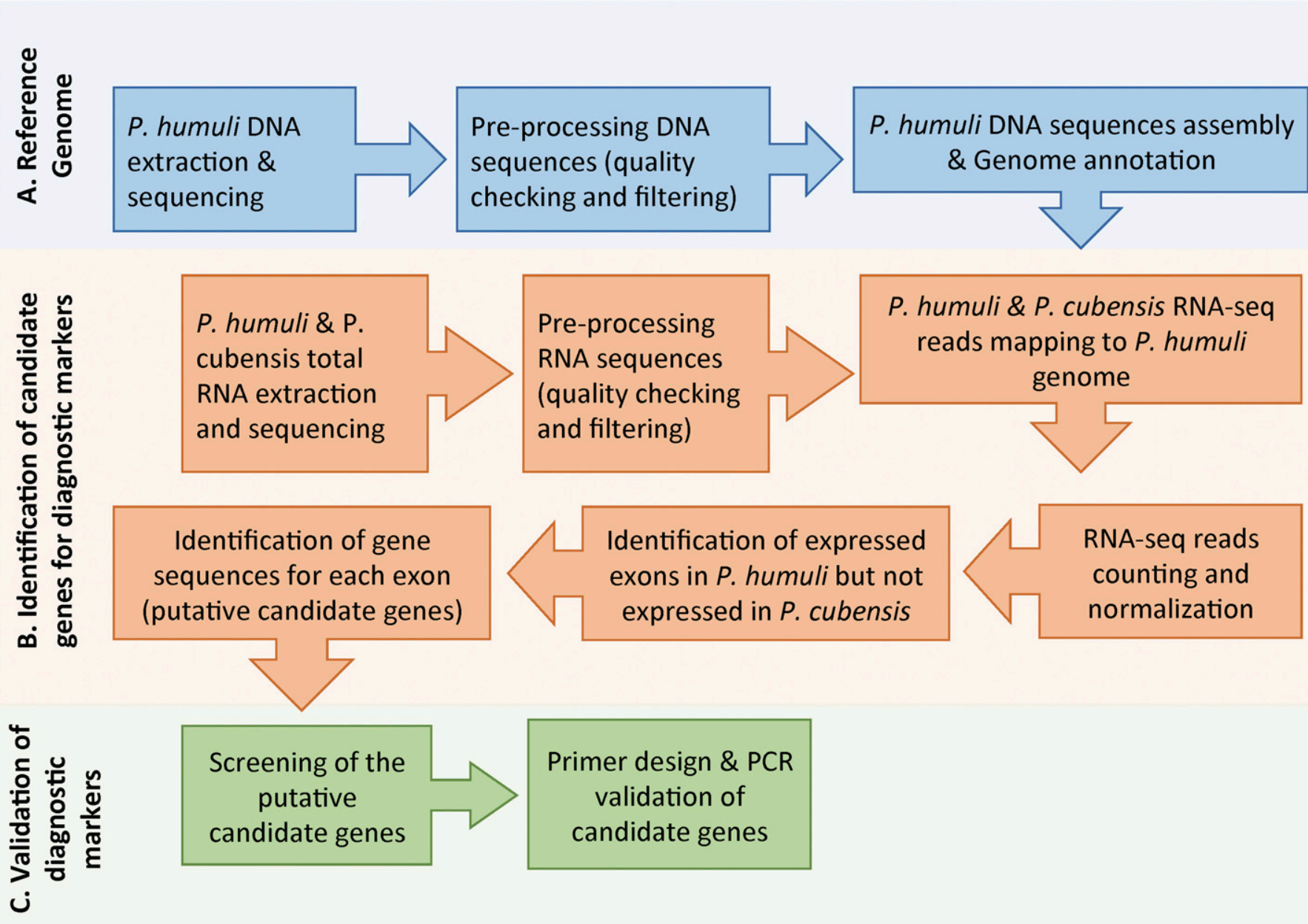

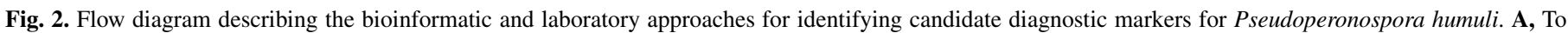

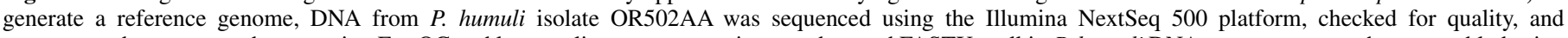

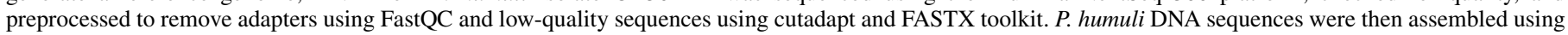

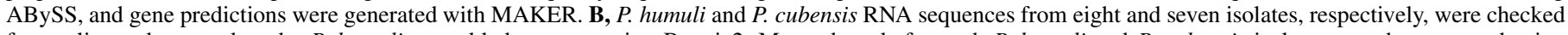

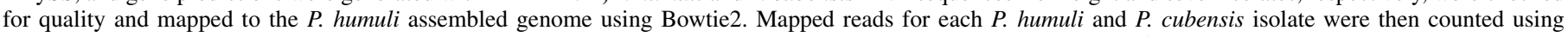

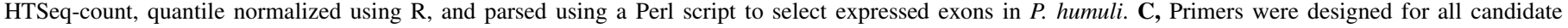
molecular marker genes and screened for polymerase chain reaction (PCR) amplification. 
Mitochondrial genome. The mitochondrial genome was assembled into a circular molecule of $39,087 \mathrm{bp}$ with a GC content of $22.2 \%$ (Fig. 4). A total of 35 known genes (encoding 18 respiratory chain proteins, 16 ribosomal proteins, and an import protein: ymfl6 of the sec Y-independent pathway), the $r n l$ and $r n s$, and 19 amino acids encoded on 25 tRNA genes were present. In addition, there were four hypothetical proteins (ymf $98, y m f 99$, $y m f 100$, and ymf101) in common with other oomycete mitochondrial genomes (Grayburn et al. 2004; Levesque et al. 2010; Martin et al. 2007) and one putative ORF (orf359) located between the $r n s$ and $\operatorname{cox} 2$ genes that is unique to $P$. humuli. BLAST queries of orf359 to GenBank identified $85 \%$ sequence identity with 1,106 bp of orf306 and flanking sequences from $P$. cubensis (KT072718). The gene order and position of the putative ORF were the same as observed in P. cubensis. The coding regions represent $90.3 \%$ of the genome, with $7.7 \%$ of this total representing hypothetical coding regions.

With the exception of a putative ORF, the observed gene order in $P$. humuli is the same as $P$. cubensis, but both species are different from Peronospora tabacina in that the rns is located in the same position but encoded in the opposite direction; this is the same for Phytophthora spp. Although the rest of the gene order is the same as Phytophthora poloncia, Phytophthora ramorum, and Phytophthora sojae, there are several inversions in comparison with Phytophthora infestans (atp9-cob and atpl-atp6) and Phytophthora nicotianae (atp9-cob). The large inverted repeats encompassing the $r n l$ and $r n s$

\section{MOLECULAR FUNCTION}

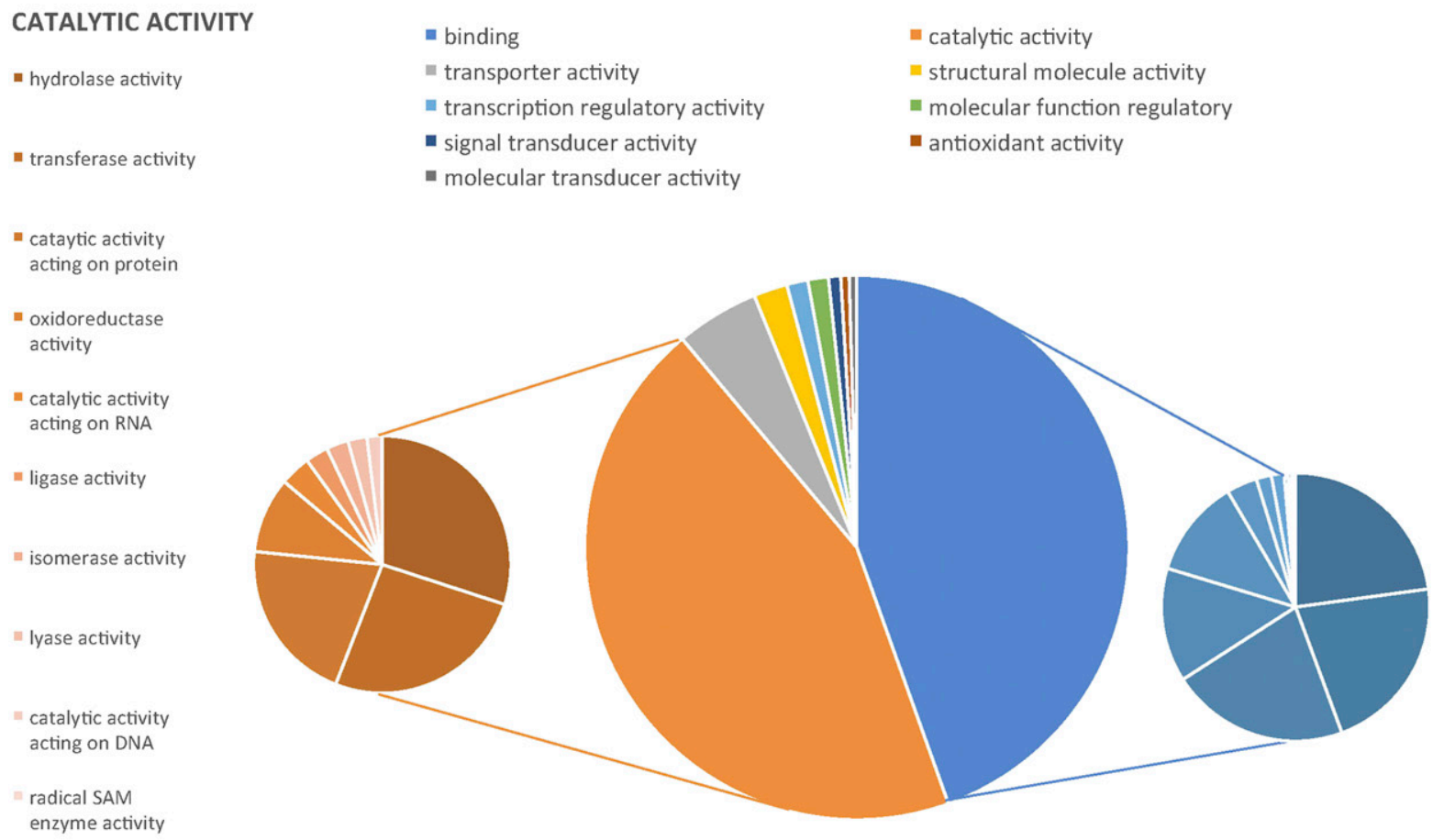

\section{BINDING}

- macromolecular complex binding - organic cyclic compund binding - heterocyclic compound binding - small molecule binding

carbohydrate derivative binding

- protein binding

" cofactor binding

- lipid binding

" carbohydrate binding

" iron-sulfur cluster binding

sulfur compound binding

polysacchaaride

binding

amide binding

- fatty-acyl-CoA

binding

chromatin binding

-FK506 binding

modified amino acid binding

Fig. 3. Assignment of Gene Ontology Slim terms for the Molecular Function category to Pseudoperonospora humuli predicted gene models. The two most represented functions in the $P$. humuli genome-catalytic activity and binding - are shown in lighter gray (orange) and darker gray (blue) small pie charts, respectively. SAM, S-adenosylmethionine; CoA, coenzyme A.

TABLE 5. Candidate pathogenicity-related genes in Pseudoperonospora humuli and other oomycete genomes

\begin{tabular}{|c|c|c|c|c|c|c|c|}
\hline Gene family & P. humuli $i^{\mathrm{a}}$ & P. cubensis $^{\mathrm{b}}$ & $\begin{array}{l}\text { Plasmopara } \\
\text { halstedii }^{\mathrm{c}}\end{array}$ & $\begin{array}{l}\text { Hyaloperonospora } \\
\text { arabidopsidis }^{\mathrm{c}}\end{array}$ & $\begin{array}{l}\text { Phytophthora } \\
\text { infestans }\end{array}$ & $\begin{array}{l}\text { Pythium } \\
\text { ultimum }^{\mathrm{c}}\end{array}$ & $\begin{array}{c}\text { Albugo } \\
\text { laibachii }^{\mathrm{c}}\end{array}$ \\
\hline ATP-binding cassette superfamily & 159 & 69 & 32 & 35 & 127 & 112 & 26 \\
\hline Phospholipase & 20 & 22 & 17 & 23 & 43 & 25 & 19 \\
\hline Lipase & 16 & 16 & 24 & 30 & 57 & 36 & 23 \\
\hline Cysteine protease family & 33 & 20 & 54 & 51 & 64 & 75 & 48 \\
\hline Serine protease family & 77 & 65 & 62 & 73 & 106 & 149 & 52 \\
\hline Aspartyl protease family & 11 & 10 & 15 & 14 & 19 & 34 & 16 \\
\hline Cutinase & 5 & 2 & 2 & 2 & 4 & 0 & 3 \\
\hline NPP1_like (necrosis-inducing proteins) & 71 & 67 & 19 & 21 & 27 & 7 & 0 \\
\hline Pectate lyase & 4 & 4 & 3 & 8 & 36 & 15 & 0 \\
\hline Cytochrome P450 & 23 & 17 & 14 & 18 & 30 & 44 & 3 \\
\hline Pectinesterase & 14 & 4 & 5 & 4 & 11 & 0 & 0 \\
\hline Elicitin & 21 & 12 & 16 & 16 & 45 & 46 & 9 \\
\hline RxLR effector family candidates & $189^{d}$ & 271 & 274 & 134 & 505 & 0 & 49 \\
\hline Crincklers (CRN family candidates) & $90^{\mathrm{d}}$ & 145 & 77 & 20 & 196 & 26 & 3 \\
\hline
\end{tabular}

a MAKER annotation of $P$. humuli genome.

b Savory et al. 2012.

c Sharma et al. 2015 .

d ShinyR packages of R version 3.4.4 (R Core Team 2017), SignalP (Petersen et al. 2011), and manual check. 
coding regions observed in Pythium spp., Salrolegnia ferax, and A. hypogyna are not observed in $P$. humuli. Although some gene orders are conserved among these taxa, the gene orders in general are more divergent in $P$. humuli (secY to $r p s 4$ ).

Identification of species-specific candidate diagnostic markers. To identify species-specific diagnostic markers, the $P$. humuli genome was used as a reference (Fig. 2). Additionally, mapping of high-quality $P$. humuli and $P$. cubensis RNA-seq reads to the H. lupulus var. lupulus genome (Natsume et al. 2015) resulted in $<10 \%$ of dataset alignment, whereas only a small percentage of P. humuli (0.58 to $0.6 \%$ ) and P. cubensis (1.72\%) DNA-seq reads aligned to the hop genome.

Exons expressed in $P$. humuli but not expressed in $P$. cubensis isolates were determined by mapping $P$. humuli and $P$. cubensis RNA-seq reads to the $P$. humuli genome. Alignments of RNA-seq reads of $P$. humuli isolates varied between 74.24 and $93.2 \%$ except for isolate JP490, which had an alignment of $51.16 \%$. For $P$. cubensis isolates, RNA-seq alignments were within a range of 61.48 to $87.1 \%$. DNA-seq read alignment of $P$. humuli and $P$. cubensis to the draft $P$. humuli genome was within a range of 49.38 to $59.4 \%$ (Fig. 2 and Table 4). Mapped RNA-seq reads were quantified, and a quantile normalization was applied to the data. Candidate genes were selected using an arbitrary criterion of a value of two quantiles or more for expressed exons and less than two quantiles for nonexpressed exons. Thus, 279 exons expressed in all $P$. humuli isolates and nonexpressed in $P$. cubensis isolates were identified. These exons were associated with 242 predicted genes, and examination of their expression across all seven $P$. humuli isolates revealed that putative candidate genes were clustered in three clades, in which $46 \%$ were expressed at low levels, $41 \%$ were moderately expressed, and only $13 \%$ were highly expressed (Fig. $5 \mathrm{~A})$. Ontologies for molecular function and biological process categories were associated with 47 and 23 of these predicted genes, respectively. Using BLASTN (query cover $80 \%$ ), the candidate gene markers were aligned to assembled transcripts from $P$. humuli OR502AA isolate, resulting in 95 of 242 putative gene markers with strong transcript support.

Functions of these 242 candidate genes included RNA binding, ATPase activity, calcium ion binding, DNA binding, and kinase and

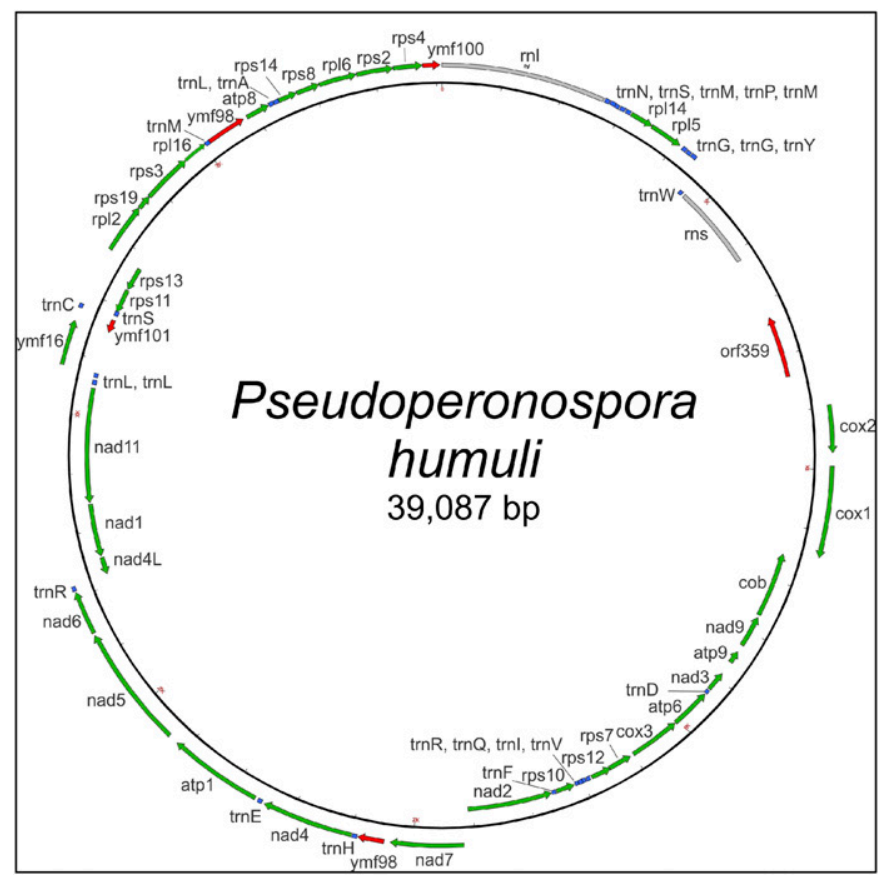

Fig. 4. Circular map of the mitochondrial genome of isolate OR502AA of Pseudoperonospora humuli. endopeptidase activity among others. Of the 23 genes associated with biological process category, 4 were found to be related to defense and pathogenesis. Interestingly, such genes were annotated as hypothetical proteins (Fig. 5B). Additionally, functional annotation revealed that 18 of the candidate gene markers were annotated as virulence related genes (CRN family, secreted RxLRs, elicitins, elicitors, and pectin esterases), 12 were annotated as glycolysis or other metabolic pathway genes, five were annotated as gene regulationrelated genes (transcription factors, protein kinase, and phosphatase), three were annotated as coenzyme Q-binding protein (CoQ10 homolog), and two were annotated as ATP-binding cassette superfamily. Of the candidate gene markers, 99 were annotated as genes of unknown function. The remaining candidate markers had functional annotations related to signaling, regulatory, and housekeeping/ constitutive genes. To further identify the marker genes with unknown function, BLAST searches performed against protein databases from Phytophthora infestans, Phytophthora capsici, and H. arabidopsidis allowed annotation of three more genes. These three genes were putatively identified as involved in functions related to ATP-binding protein kinase (c124513.0e2), virulence (c124754.15e1), and signaling (c125755.11e2). Additional searches using the Pfam database identified the presence of protein domains in three more candidate marker genes with unknown function: c127532.8e3 as an Mlo protein (PF03094.13) with 7.1 $\mathrm{e}^{-06} \mathrm{e}$ value, c124006.2e2 as a ribosomal protein with $\mathrm{S} 15$ (PF00312.20) with $1.8 \mathrm{e}^{-04} \mathrm{e}$ value, and $125745.4 \mathrm{e} 1$ as ubiE/ COQ5 methyltransferase family protein (PF01209.16) with $3.1 \mathrm{e}^{-12} \mathrm{e}$ value. A self-BLASTX analysis revealed that all but one were putative single-copy genes.

Validation of species-specific diagnostic markers. All 242 candidate genomic markers were chosen for PCR validation of specificity with diverse $P$. humuli isolates. This initial PCR screening with $10 \mathrm{P}$. humuli isolates resulted in a single PCR amplicon for 39 candidate genomic markers that matched with their corresponding predicted amplicon sizes. For the remaining 202 candidate markers, 163 exhibited amplification for only some or none of the $10 \mathrm{P}$. humuli isolates, and 39 candidate markers produced multiple or variable PCR amplicons among the isolates. Therefore, these markers were not pursued in subsequent experiments. The 39 candidate markers that produced single-PCR amplicons were then evaluated against five $P$. cubensis isolates; 10 of these 39 candidate markers produced either no or readily distinguishable PCR amplicons, and they were chosen for the final PCR validation with 59 diverse isolates. The final PCR screen included an additional 15 isolates of $P$. humuli, 23 isolates of $P$. cubensis, five isolates of Peronospora belbahrii, two isolates of Pl. obducens, six isolates of Phytophthora spp., six isolates of Pythium spp., and two host plants (cucumber and hop). After the final screening, 4 of 10 candidate gene markers (c125015.3e1, c127446.1e1, c127233.5e3, and c126365.1e5) exhibited a single distinguishable PCR amplicon in all $P$. humuli isolates compared with other isolates and samples tested (Figs. 6 and 7 and Table 6). These four candidate genomic regions were, therefore, considered highly specific molecular markers for P. humuli.

All four of these genes were putative single-copy genes according to self-BLASTX against the MAKER standard predicted proteins of $P$. humuli. Three (c127233.5e3, c127446.1e1, and c126365.1e5) of these four genes were found to be of nuclear origin with unknown functions, whereas one (c125015.3e1) was annotated as a homolog of COQ10, a coenzyme Q-binding protein, which is typically a mitochondrial gene. However, additional BLAST queries of $\mathrm{c} 125015.3 \mathrm{e} 1$ to GenBank did not identify significant sequence similarity with any known oomycete mitochondrial genes. In addition, c125015.3e1 was not observed in the assembled mitochondrial genome. Except for $P$. humuli isolates, none of the samples tested were found to produce any PCR amplicons for the c125015.3e1 gene, whereas only some P. cubensis isolates produced PCR products of different size for the other three marker 
genes. None of the four candidate genomic makers exhibited any size polymorphism among the $P$. humuli samples tested.

\section{DISCUSSION}

The assembled draft genome of $P$. humuli has a size of $40.6 \mathrm{Mb}$ and reflects a partial assembly smaller than those published for other downy mildew pathogens, such as Hy. arabidopsidis (78.9 $\mathrm{Mb}$ ) and Pl. viticola (101.3 Mb) (Sharma et al. 2015; Yin et al. 2017). Previous studies have estimated the $P$. humuli genome size to be between 75 and $80 \mathrm{Mb}$ (Voglmayr and Greilhuber 1998). Nonetheless, a quick statistical analysis of DNA-seq reads $k$-mer profiles with GenomeScope (Vurture et al. 2017) provided a $P$. humuli OR502AA genome length of $47.2 \mathrm{Mb}$, which correlates better to the assembled genome size estimate than the previous estimates. Provided that $P$. humuli has a diploid genome and that OR502AA DNA-seq reads coverage is $100 \times$ (GenomeScope requires a diploid genome and a minimum coverage of $25 \times$ ), it is conceivable that the GenomeScope estimated length of the $P$. humuli genome is more precise than the length initially estimated by Voglmayr and Greilhuber (1998). The CEGMA analyses indicated 97.8 and $98.9 \%$ of complete and partial core eukaryotic gene representations, respectively, whereas $<80 \%$ of BUSCO core genes were identified in our P. humuli OR502AA genome assembly, likely reflecting an incomplete nature of the assembly. Regardless, such difference in genome estimation warrants a more complete genome assembly, preferably using third generation sequencing technologies, such as single-molecule, real-time sequencing technique(s).
Elimination of bacterial contaminant DNA data using Blobology tools likely resulted in a more fragmented assembly but of higher quality with a lower number of scaffolds and higher N50 than that of the P. cubensis draft genome (Savory et al. 2012). Additionally, the high percentages from CEGMA and BUSCO reports suggest that the gene space regions from this partial genome assembly can be used in genecalling pipelines as reported in other oomycetes, such as Albugo laibachii (Kemen et al. 2011). Although partial, this is the first reported genome assembly of $P$. humuli, an important pathogen of hop, and it will serve as a draft genome assembly until a more complete genome assembly is generated. The release of the $P$. humuli draft genome is a valuable addition to the oomycete genome resources, especially of downy mildew pathogens, that will provide important insights about the biotrophic lifestyle, and it will serve as a resource for studying coevolution of host and obligate pathogens and speciation owing to host adaptation and reproductive isolation.

UniProtKB, InterPro, and Pfam annotations revealed a plethora of pathogenicity-related proteins, which are described in Table 5. The number of putative pathogenicity-associated proteins identified in the $P$. humuli genome was broadly similar to that identified in other oomycete pathogens. Although the total number of candidate RXLR-type effectors identified in $P$. humuli is less than that reported in P. cubensis (Savory et al. 2012) and Pl. halstedii (Sharma et al. 2015), it is higher than in $H y$. arabidopsidis (Table 5). Additionally, most of the variants of RXLR motifs, such as QXLR identified in $P$. humuli, lack the EER motif (Fig. 4) unlike its sister species P. cubensis, where all 47 QXLR motifs were noted to have EER motifs (Tian et al. 2011). However, although most of the putative RXLR effectors (93 of
A
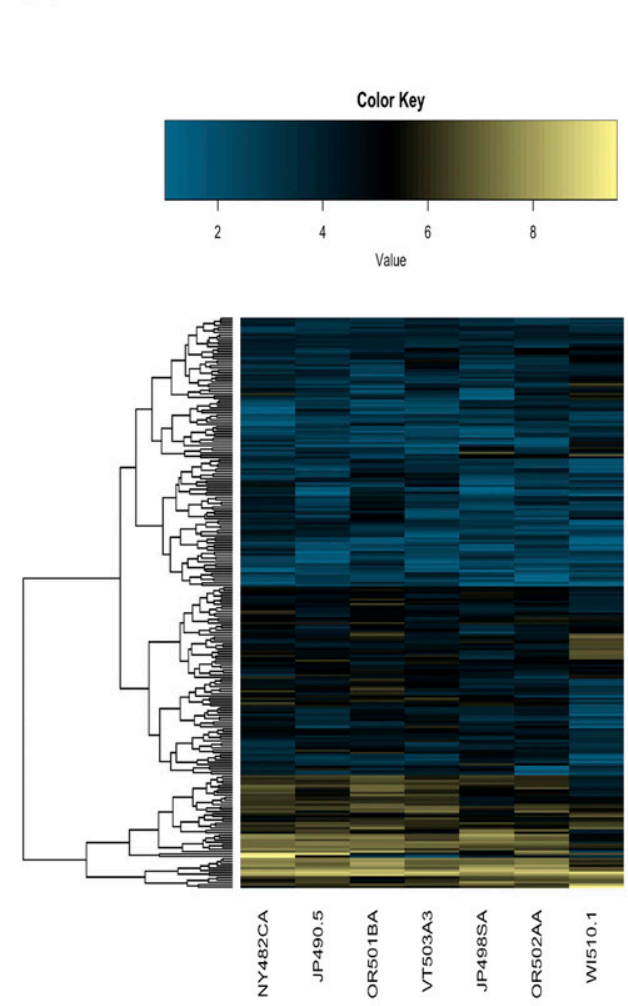

B

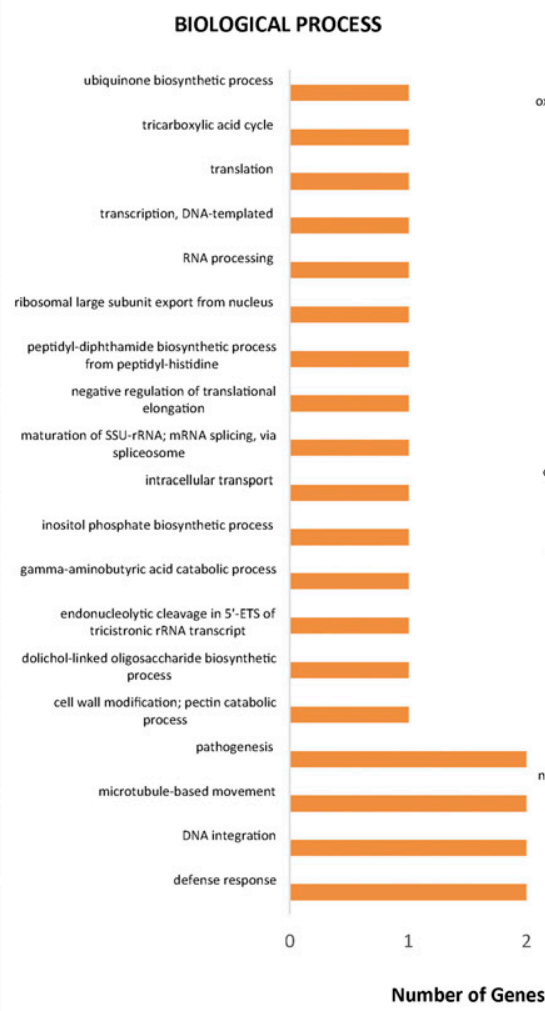

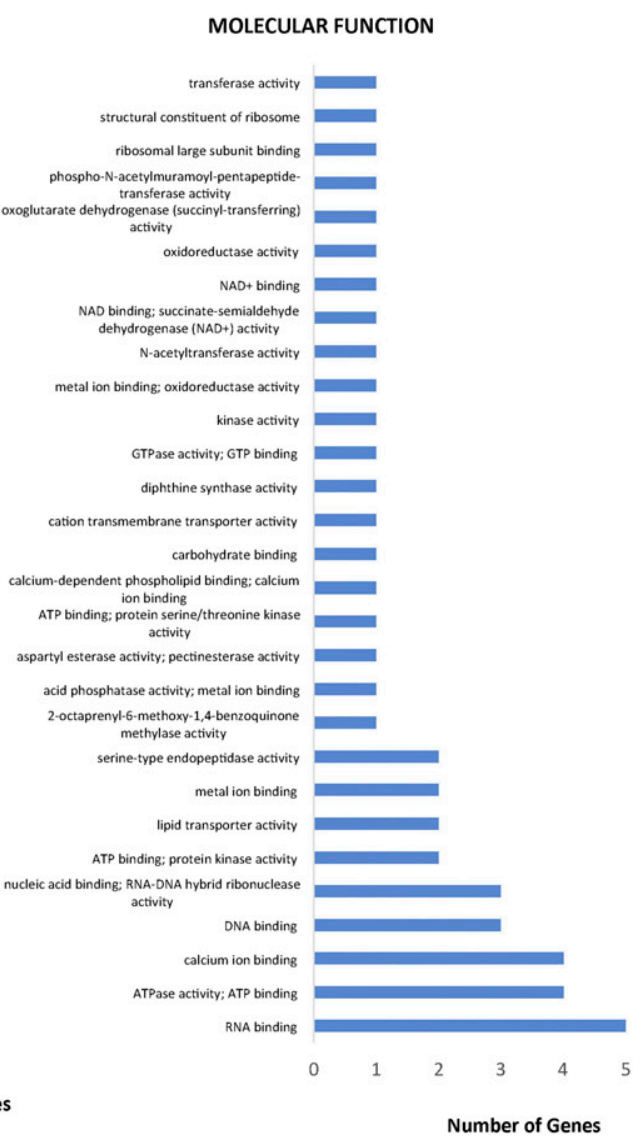

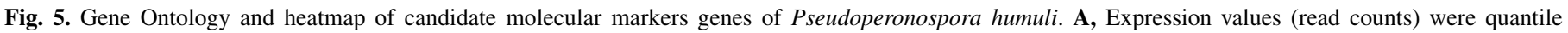

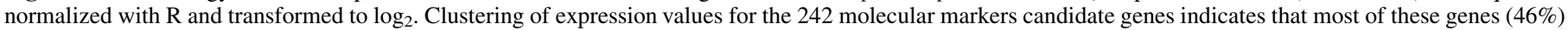

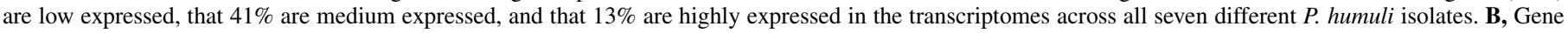

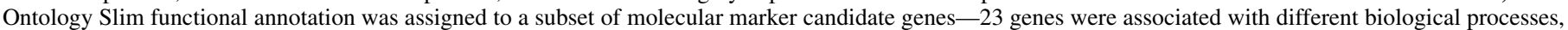

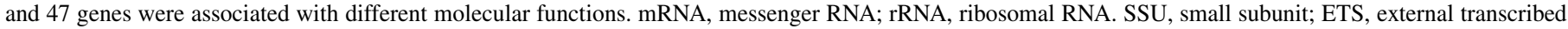
spacer. 
101) identified in $P$. humuli are RXLR-EER type, only 34 of 274 of RXLR-like effectors have been found in Pl. halstedii to have EER.

This raises an interesting question about the conserved role of RXLR-like motifs in conjunction with EER for protein translocation in different oomycete species and is suggestive of involvement of additional proteins (Sharma et al. 2015). It should also be noted that the partial nature of the assembled genome of $P$. humuli could contribute to the identification of a lower number of effector genes compared with its sister species $P$. cubensis.

Crinkler (CRN) family proteins, which are known to suppress host immunity and belong to an ancient class of cytoplasmic effectors, have been documented in the genomes of all sequenced oomycete pathogens (Sharma et al. 2015). Of 49 CRN-like proteins identified, only four were noted to have both LFLAK and HVLV motifs, and the rest exhibited the presence of either of the two motifs. Surprisingly, 47 of 49 proteins with a CRN signature in $P$. humuli were not predicted to carry a signal sequence for secretion. However, similar absence of signal peptide has also been noted in CRN family proteins in Pl. halstedii (Sharma et al. 2015). The role of these putative CRN family proteins in pathogenicity or cellular functions remains to be investigated.

The RNA-seq data used in this study for identifying $P$. humuli species-specific diagnostic markers were checked for quality and preprocessed in our previous study (Withers et al. 2016), thereby ensuring the quality of the reads used. Obtaining good quality genomic DNA or RNA from obligate pathogens can be challenging because of the possibility of recovering a mixture of host and other phyllosphere microbial DNA/RNA together with target pathogen nucleic acids. As a result, alignment of a very low percentage $(<10 \%)$ of the RNA-seq reads of $P$. humuli and $P$. cubensis isolates with the hop genome was not unexpected. However, RNA-seq reads of almost all $P$. humuli isolates mapped to the $P$. humuli draft genome to a considerably higher extent $(>74 \%)$. Because infected hop leaves used to grow isolates cannot be completely sterilized, the presence of contaminating microbial DNA and RNA in the NGS dataset used in this study was anticipated. Presence of contaminating nucleic acid sequences from phyllosphere microorganisms in other obligate oomycetes NGS datasets has also been noted (Burkhardt and Day 2016; Guo et al. 2016; Sharma et al. 2015).

Although strong transcriptional evidence was noted in 95 of 242 candidate gene markers, none of them generated PCR amplicons in all tested $P$. humuli isolates, and some were amplified in $P$. cubensis isolates under the PCR conditions used. This could be owing to multiple reasons, such as presence/absence of sequence polymorphism in primer annealing sites, indels making the target too large for the amplification conditions used in $P$. humuli isolates, and/or the unfinished quality (N50 contig size of $4.0 \mathrm{~kb}$ ) of the $P$. cubensis genome, which allowed false identification of exons as unique in $P$. humuli. One of the advantages of developing markers

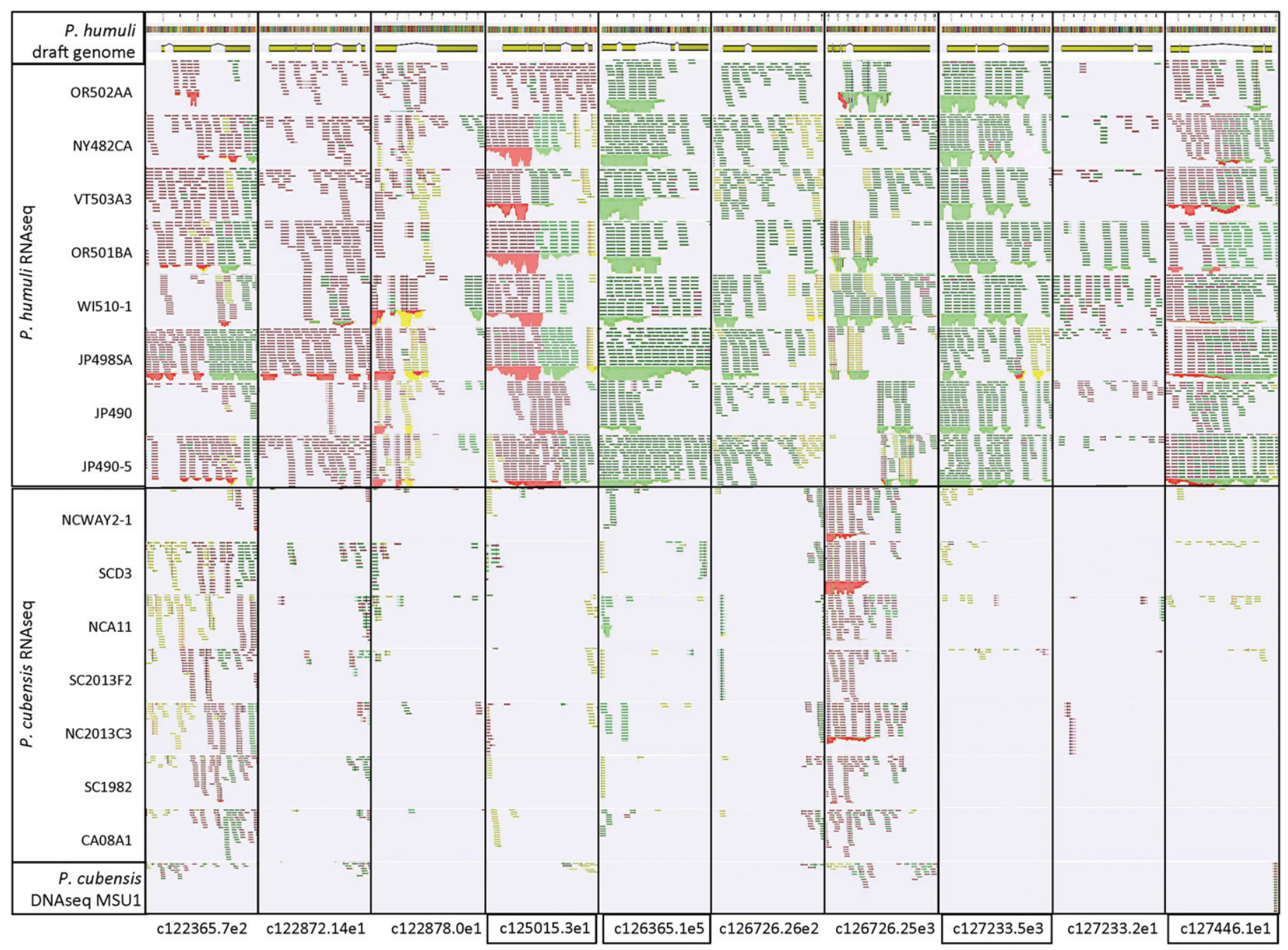

Fig. 6. Use of next generation sequencing data to identify species-specific regions in Pseudoperonospora humuli utilizing comparative genomics with closely related sister species $P$. cubensis. The $P$. humuli genome panel shows four predicted genes in $P$. humuli that have missing exons in the $P$. cubensis DNA-seq. A diverse panel of RNA-seq data from $P$. humuli and $P$. cubensis isolates (Table 1) was mapped against the $P$. humuli genome to detect transcripts consistently present in $P$. humuli but not in P. cubensis. Images were generated using CLC Genomics Workbench (CLCbio). 
based on transcriptome evidence is that such markers are associated with functional genes (Fig. 7), which could be used for pathogen detection in combination with tracking a particular phenotype governed by the gene (Wallace and Quesada-Ocampo 2017). A number of candidate genes encoding virulence-related proteins, including RXLR, CRN, and elicitors, were identified as $P$. humuli species specific. Variation or divergence in effector repertoires has been proposed to play an important role in ecological speciation, resulting in host jump or host range expansion (Schulze-Lefert and Panstruga 2011). In plant pathogens, especially in obligate parasites, it is expected that host adaptation, host range expansion, and host jumps are major mechanisms driving speciation (Stukenbrock 2013). Because of high genetic similarities between the two sister species $P$. humuli and $P$. cubensis, additional investigation of these stressrelated candidate marker genes could shed light on their role in host adaptation of $P$. humuli. Although none of the effector or virulence-related genes made it to the final four candidate markers for $P$. humuli, c125015.3e1 was consistently amplified in all $P$. humuli isolates but not in any other species' DNA tested. Although our functional annotation pipeline identified c125015.3e1 as a homolog of the mitochondrial CoQ10 protein, additional BLAST analyses did not provide any significant homology between c125015.3e1 and available CoQ10 DNA sequences on the NCBI database. It was, therefore, designated as a gene with unknown function in our final analyses (Table 6). However, CoQ10 is a conserved CoQ-binding protein that shuttles CoQ to the catalytic sites of the respiratory chain (Barros et al. 2005). This makes $\mathrm{c} 125015.3 \mathrm{e} 1$ a potential candidate gene for additional investigation of genetic mechanisms that are involved in adaptation of $P$. humuli on hop. Additionally, 99 of 242 candidate marker genes were annotated as genes with unknown function; whether these genes play any role in host specialization of $P$. humuli is unknown. Notably, a set of genes of unknown function exhibited strong positive selection in Mycosphaerella graminicola infecting wheat and have been speculated to be involved in host specialization (Stukenbrock et al. 2010).

The mitochondrial genome of $P$. humuli is circular and $\sim 39 \mathrm{~kb}$, which is similar in size to what is observed for P. cubensis $(38.5 \mathrm{~kb})$, Peronospora tabacina (43 kb), Phytophthora spp. ( 38 to $43 \mathrm{~kb})$, and Pythium ultimum (37.7 kb with only one arm of the inverted repeat, $59.7 \mathrm{~kb}$ total). The mitochondrial genome encodes the same standard suite of genes, including the putative ORFs ymf16, ymf 98 , ymf 99 , $y m f 100$, and ymf101, such as has been reported for the genus Phytophthora (Martin et al. 2007) and Pythium ultimum (Levesque et al. 2010) as well as S. ferax (Grayburn et al. 2004), A. hypogyna, and Thraustotheca clavata (O'Brien et al. 2014). There is also an additional putative ORF of unknown function encoded between the $r n s$ and cox 2 genes that shares some level of sequence identity with a putative ORF in the same location as with P. cubensis (KT072718). An inverted repeat that is present in some oomycetes (Grayburn et al. 2004;
Hudspeth et al. 1983; Levesque et al. 2010; McNabb et al. 1987; O'Brien et al. 2014) is not observed in P. humuli.

In general, the mitochondrial gene order in P. humuli is similar to what was observed in other downy mildews and the genus Phytophthora with some exceptions. One notable difference, which was also observed in P. cubensis (KT072718), was that the $r n s$ is encoded in the opposite orientation in $P$. humuli in comparison with Peronospora tabacina and Phytophthora spp. Other than this, the gene order was the same as observed in Peronospora tabacina and P. cubensis. With the exception of $r n s$, the same gene order was also observed in Phytophthora ramorum (DQ82718) and Phytophthora sojae (DQ82717), but in comparison with Phytophthora infestans and other clade $1 \mathrm{C}$ species, there were two inversions: cob-atp 9 and nad3-atp1 (NC002387, AY898627, AY898628, AY894835, HM590418, HM590419, HM590420, and HM590421). Using a similar approach that was used for developing a diagnostic assay for Bremia lactucae (Kunjeti et al. 2016), the mitochondrial genome of $P$. humuli is also being used to develop a mitochondrial-based detection assay (M. Ramon, A. Burkhardt, and F. N. Martin, personal communication).

In earlier studies, nuclear ITS and mitochondrial cox 2 region have been utilized for developing $P$. humuli detection markers (Gent et al. 2009; Summers et al. 2015). However, these markers either could not differentiate between P. humuli and P. cubensis (Gent et al. 2009) or were based on a single-nucleotide polymorphism (SNP) (Summers et al. 2015). Nonetheless, the detection limit of SNP-based real-time PCR assays may exhibit high variability (Psifidi et al. 2011). NGS technologies have been used in several studies, where total DNA and/or RNA were used for the identification of unique regions or sequence variation in nuclear or other cell organelle DNA for diagnostic purposes (De Boer and Lopez 2012; Studholme et al. 2011; Withers et al. 2016). To our knowledge, this is the first report of species-specific $P$. humuli exons or genes that can be used for identification and diagnostics from its closely related sister species $P$. cubensis. Although 242 speciesspecific candidate exons in 241 genes were identified, based on comparative genomics analyses, not all of the markers amplified during PCR validation screen. This could be because of, among other reasons, designing the PCR primers within 200-bp upstream and downstream regions of each gene's start codon, which might differ among the $P$. humuli isolates and therefore, fail to amplify. Similarly, the 39 candidate genes eliminated after the first round of PCR screening owing to either absence or generation of multiple and/ or differential amplicons could be because of PCR primer crossreaction, amplification stringency, or polymorphism. Allelic polymorphism has been detected in P. cubensis (Withers et al. 2016) using similar techniques of candidate marker development; additional investigation is required to confirm any such allelic polymorphism in P. humuli.

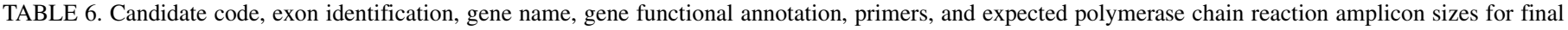
Pseudoperonospora humuli species-specific candidate genomic markers

\begin{tabular}{|c|c|c|c|c|c|c|}
\hline $\begin{array}{l}\text { Candidate } \\
\text { code }\end{array}$ & Exon identification $^{\mathrm{a}}$ & Gene name & $\begin{array}{c}\text { Gene } \\
\text { functional } \\
\text { annotation }\end{array}$ & Primer & Sequence & $\begin{array}{l}\text { Expected } \\
\text { product } \\
\text { size }\end{array}$ \\
\hline $\mathrm{c} 125015.3 \mathrm{e} 1$ & $\begin{array}{l}\text { maker-contig_125015-augustus- } \\
\text { gene-0.3-mRNA-1:1 }\end{array}$ & Phum_OR502AA_v1_g_09538 & $\begin{array}{l}\text { Gene of } \\
\text { unknown } \\
\text { function }\end{array}$ & $\begin{array}{l}\text { Forward } \\
\text { Reverse }\end{array}$ & $\begin{array}{l}\text { GCTTCCTTTGCGGTACATA } \\
\text { TTGTATGAACTTTGATGCATGT }\end{array}$ & 639 \\
\hline c127446.1e1 & $\begin{array}{l}\text { maker-contig_127446-snap- } \\
\text { gene-0.1-mRNA-1:1 }\end{array}$ & Phum_OR502AA_v1_g_00649 & $\begin{array}{l}\text { Gene of } \\
\text { unknown } \\
\text { function }\end{array}$ & $\begin{array}{l}\text { Forward } \\
\text { Reverse }\end{array}$ & $\begin{array}{l}\text { AGCCCTAGGAAATTTCATCTTT } \\
\text { ATTTGCTTCTTGGTCATTGAAA }\end{array}$ & 632 \\
\hline $\mathrm{c} 127233.5 \mathrm{e} 3$ & $\begin{array}{l}\text { maker-contig_127233-snap-gene- } \\
0.5 \text {-mRNA-1:3 }\end{array}$ & Phum_OR502AA_v1_g_12093 & $\begin{array}{l}\text { Gene of } \\
\text { unknown } \\
\text { function }\end{array}$ & $\begin{array}{l}\text { Forward } \\
\text { Reverse }\end{array}$ & $\begin{array}{l}\text { ATACCAAGCACAAGAACAACTA } \\
\text { CGTAGTCGCAGTAGATCAC }\end{array}$ & 860 \\
\hline c126365.1e5 & $\begin{array}{l}\text { maker-contig_126365-snap-gene- } \\
\text { 0.1-mRNA-1:5 }\end{array}$ & Phum_OR502AA_v1_g_16807 & $\begin{array}{l}\text { Conserved } \\
\text { gene of } \\
\text { unknown } \\
\text { function }\end{array}$ & $\begin{array}{l}\text { Forward } \\
\text { Reverse }\end{array}$ & $\begin{array}{l}\text { ATTCCAATACAAGCACTTCTCT } \\
\text { GATCTGCAGTGATTCCATAATG }\end{array}$ & 1,425 \\
\hline
\end{tabular}

a mRNA, messenger RNA. 
Methods utilizing a combination of PCR-based technologies and spore traps have been developed for species-specific detection of downy mildew pathogens of spinach (Peronospora effusa), beet (Peronospora schachtii) (Klosterman et al. 2014), lettuce (B. lactucae) (Kunjeti et al. 2016), cucumber (P. cubensis), and hop ( $P$. humuli) (Gent et al. 2009; Summers et al. 2015). Sensitivity and specificity of detection to the target organism are of paramount importance for developing such a detection method to avoid cross-detection. Species-specific exons or genes of $P$. humuli identified and PCR validated in this study can be implemented when developing similar DNA-based detection methods, such as quantitative real-time PCR and loop-mediated isothermal amplification. Although hop production in the western United States does not overlap with cucurbit production (Gent et al. 2009), this is not always the case in the East Coast or Midwest regions of the United States, such as in the western part of North Carolina, where cucurbits and hop are grown in the same production regions (Rahman et al. 2017). Because of the systemic growth of $P$. humuli (Gent et al. 2009) in hop and possible presence of aerial sporangia of $P$. cubensis from infected cucurbit plants in the same area, markers identified in this study could be extremely valuable for development of a robust pathogen detection system in symptomless tissues to verify that planting materials are free of $P$. humuli, which is an important source of initial inoculum (Skotland and Johnson 1983). The markers could also be valuable for early detection of aerial $P$. humuli sporangia for timing fungicide applications and improving management of hop downy mildew (Gent et al. 2009).

Conclusion. Whole-genome sequencing and comparative genomics approaches to identify $P$. cubensis species-specific markers have been successfully applied in a previous study (Withers et al. 2016), and similar approaches in combination with sequencing of the $P$. humuli draft genome allowed us to identify species-specific gene markers for $P$. humuli. Currently, there is a growing demand for high-quality hop in the United States and other parts of the world, because beer has become the most widely consumed alcoholic beverage in the world (Natsume et al. 2015). With an increase in production and resurrection of hop growing in the Eastern and Midwestern United States, hop downy mildew has the potential to become more widespread. Additionally, because of increasing atmospheric moisture content in the Eastern and Midwestern United States (Hill 2018), management of any inseason downy mildew on hop will pose significant challenges and therefore, underlines the necessity of rapid diagnosis and more sustainable disease management strategies. Because detection of $P$. humuli-infected plant materials as well as biosurveillance of airborne inoculum require robust genetic markers for accurate diagnosis, the species-specific candidate genomic markers for $P$. humuli identified in this study will pave the way for the development of rapid molecular diagnostic techniques.

\section{P. humuli}
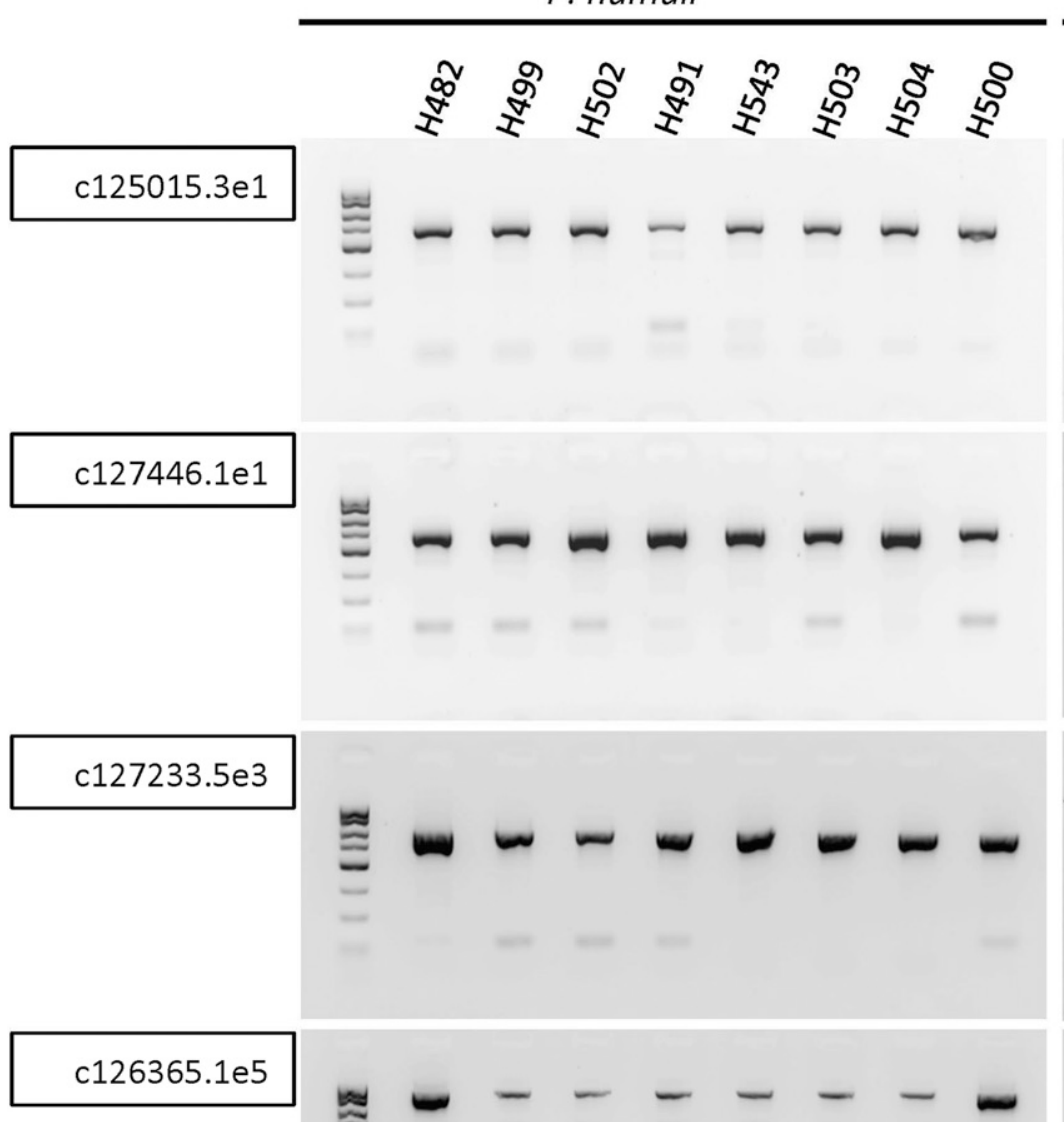

$\mathrm{c} 127446.1 \mathrm{e} 1$

c125015.3e1

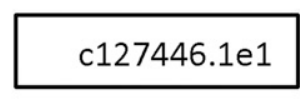

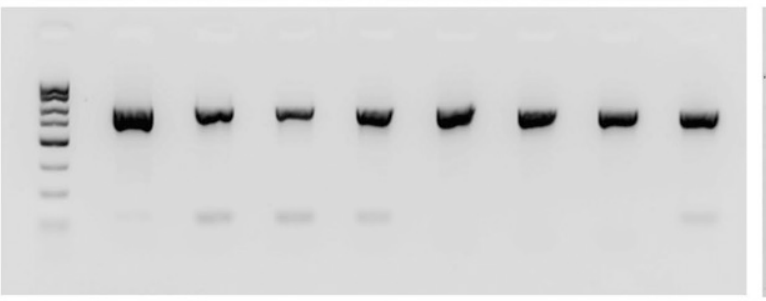

(
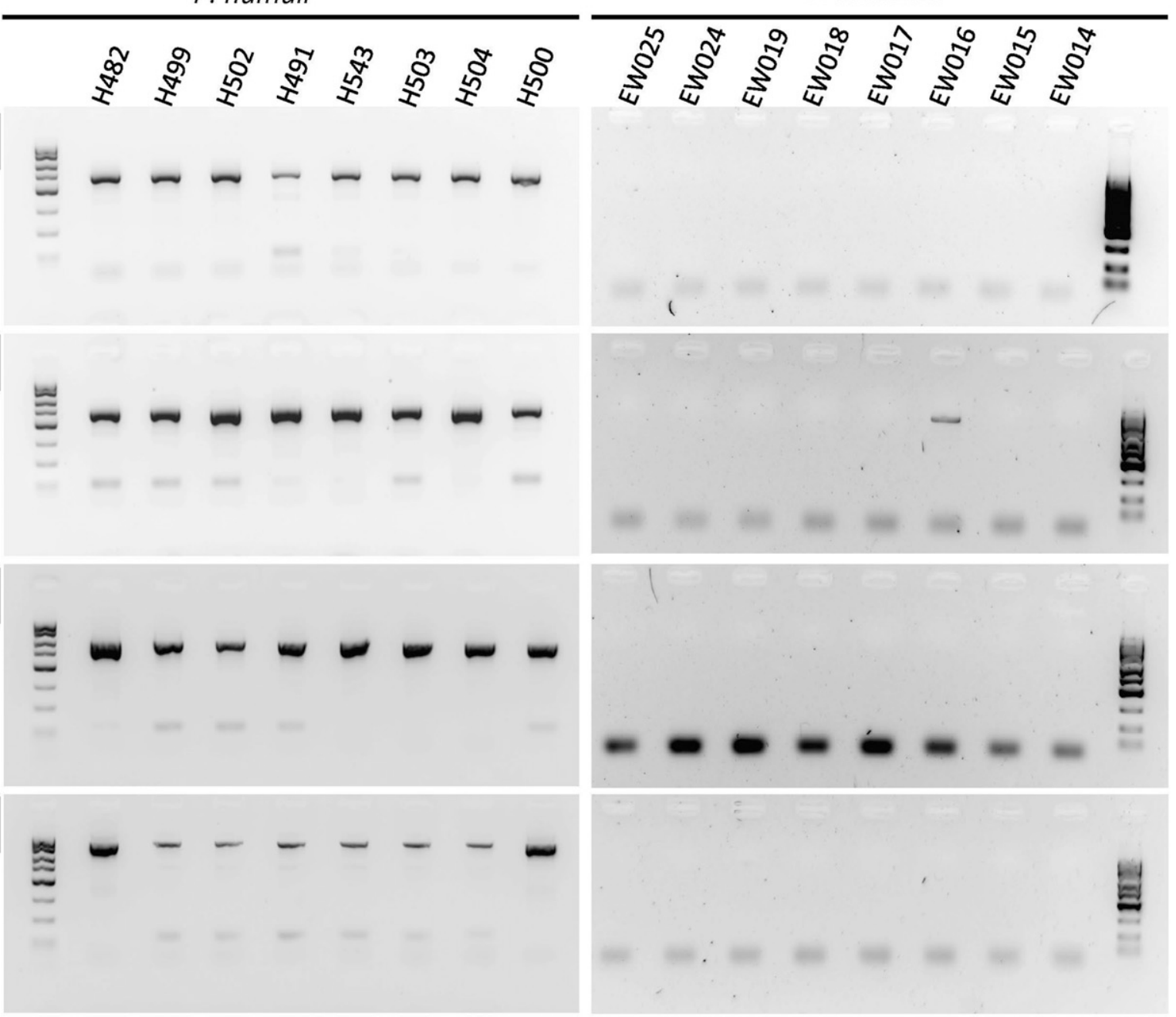

Fig. 7. Gel electrophoresis images of polymerase chain reaction amplicons of four Pseudoperonospora humuli candidate diagnostic molecular marker genes (c125015.3e1, c127446.1e1, c127233.5e3, and c126365.1e5) for diverse hop downy mildew and cucurbit downy mildew samples. Table 6 shows primer information, and Supplementary Table S1 shows isolate information. 


\section{ACKNOWLEDGMENTS}

We thank the members of the laboratory of L. M. Quesada-Ocampo for their valuable help and acknowledge the technical assistance of $\mathrm{N}$. Adair.

\section{LITERATURE CITED}

Altschul, S. F., Gish, W., Miller, W., Myers, E. W., and Lipman, D. J. 1990. Basic local alignment search tool. J. Mol. Biol. 215:403-410.

Anders, S., Pyl, P. T., and Huber, W. 2015. HTSeq-a Python framework to work with high-throughput sequencing data. Bioinformatics 31:166-169.

Andrews, S. 2012. FastQC: A Quality Control Tool for High Throughput Sequence Data. Babraham Bioinformatics, Babraham Institute. http:// www.bioinformatics.babraham.ac.uk/projects/fastqc/

Barros, M. H., Johnson, A., Gin, P., Marbois, B. N., Clarke, C. F., and Tzagoloff, A. The Saccharomyces cerevisiae COQ10 gene encodes a START domain protein required for function of coenzyme $\mathrm{Q}$ in respiration. J. Biol. Chem. 280:42627-42635.

Baxter, L., Tripathy, S., Ishaque, N., Boot, N., Cabral, A., Kemen, E., Thines, M., Ah-Fong, A., Anderson, R., Badejoko, W., Bittner-Eddy, P., Boore, J. L., Chibucos, M. C., Coates, M., Dehal, P., Delehaunty, K., Dong, S., Downton, P., Dumas, B., Fabro, G., Fronick, C., Fuerstenberg, S. I., Fulton, L., Gaulin, E., Govers, F., Hughes, L., Humphray, S., Jiang, R. H., Judelson, H., Kamoun, S., Kyung, K., Meijer, H., Minx, P., Morris, P., Nelson, J., Phuntumart, V., Qutob, D., Rehmany, A., Rougon-Cardoso, A., Ryden, P., Torto-Alalibo, T., Studholme, D., Wang, Y., Win, J., Wood, J., Clifton, S. W., Rogers, J., Van den Ackerveken, G., Jones, J. D., McDowell, J. M., Beynon, J., and Tyler, B. M. 2010. Signatures of adaptation to obligate biotrophy in the Hyaloperonospora arabidopsidis genome. Science 330: 1549-1551.

Birch, P. R. J., Armstrong, M., Bos, J., Boevink, P., Gilroy, E. M., Taylor, R. M., Wawra, S., Pritchard, L., Conti, L., Ewan, R., Whisson, S. C., van West, P., Sadanandom, A., and Kamoun, S. 2009. Towards understanding the virulence functions of RXLR effectors of the oomycete plant pathogen Phytophthora infestans. J. Exp. Bot. 60:1133-1140.

Birch, P. R. J., Boevink, P. C., Gilroy, E. M., Hein, I., Pritchard, L., and Whisson, S. C. 2008. Oomycete RXLR effectors: Delivery, functional redundancy and durable disease resistance. Curr. Opin. Plant Biol. 11:373-379.

Birch, P. R. J., Rehmany, A. P., Pritchard, L., Kamoun, S., and Beynon, J. L. 2006. Trafficking arms: Oomycete effectors enter host plant cells. Trends Microbiol. 14:8-11.

Bolstad, B. M., Irizarry, R. A., Astrand, M., and Speed, T. P. 2003. A comparison of normalization methods for high density oligonucleotide array data based on variance and bias. Bioinformatics 19:185-193.

Bozkurt, T. O., Schornack, S., Banfield, M. J., and Kamoun, S. 2012. Oomycetes, effectors, and all that jazz. Curr. Opin. Plant Biol. 15:483-492.

Burkhardt, A., and Day, B. 2016. Transcriptome and small rnaome dynamics during a resistant and susceptible interaction between cucumber and downy mildew. Plant Genome 9:1.

Cantarel, B. L., Korf, I., Robb, S. M., Parra, G., Ross, E., Moore, B., Holt, C., Sanchez Alvarado, A., and Yandell, M. 2008. MAKER: An easy-to-use annotation pipeline designed for emerging model organism genomes. Genome Res. 18:188-196.

Chee, H. Y., Nelson, M. E., Grove, G. G., Eastwell, K. C., Kenny, S. T., and Klein, R. E. 2006. Population biology of Pseudoperonospora humuli in Oregon and Washington. Plant Dis. 90:1283-1286.

Coley-Smith, J. R. 1962. Overwintering of hop downy mildew Pseudoperonospora humuli (Miy. and Tak.). Wilson. Annal Appl. Biol. 50:235-243.

Coley-Smith, J. R. 1964. Persistence and identification of downy mildew Pseudoperonospora humuli (Miy. and Tak.) Wilson in hop rootstocks. Ann. Appl. Biol. 53:129-132.

Crandall, S. G., Rahman, A., Quesada-Ocampo, L. M., Martin, F. N., Bilodeau, G. J., and Miles, T. D. 2018. Advances in diagnostics of downy mildews: Lessons learned from other oomycetes and future challenges. Plant Dis. 102:265-275.

De Boer, S. H., and Lopez, M. M. 2012. New grower-friendly methods for plant pathogen monitoring. Annu. Rev. Phytopathol. 50:197-218.

Derevnina, L., Chin-Wo-Reyes, S., Martin, F., Wood, K., Froenicke, L., Spring, O., and Michelmore, R. 2015. Genome sequence and architecture of the tobacco downy mildew pathogen Peronospora tabacina. MPMI 28: 1198-1215.

Dodds, P. N., Rafiqi, M., Gan, P. H. P., Hardham, A. R., Jones, D. A., and Ellis, J. G. 2009. Effectors of biotrophic fungi and oomycetes: Pathogenicity factors and triggers of host resistance. New Phytol. 183: 993-1000.

Dussert, Y., Gouzy, J., Richart-Cervera, S., Mazet, I. D., Delière, L., Couture, C., Legrand, L., Piron, M.-C., Mestre, P., and Delmotte, F. 2016. Draft genome sequence of Plasmopara viticola, the grapevine downy mildew pathogen. Genome Announc. 4:e00987-16.

Gent, D. H., Cohen, Y., and Runge, F. 2017. Homothallism in Pseudoperonospora humuli.. Plant Pathol. 66:1508-1516.

Gent, D. H., Nelson, M. E., Farnsworth, J. L., and Grove, G. G. 2009. PCR detection of Pseudoperonospora humuli in air samples from hop yards. Plant Pathol. 58:1081-1091.

Gent, D. H., Nelson, M. E., and Grove, G. G. 2008. Persistence of phenylamide insensitivity in Pseudoperonospora humuli. Plant Dis. 92:463-468.

Gent, D. H., and Ocamb, C. M. 2009. Predicting infection risk of hop by Pseudoperonspora humuli. Phytopathology 99:1190-1198.

Grayburn, W. S., Hudspeth, D. S. S., Gane, M. K., and Hudspeth, M. E. S. 2004. The mitochondrial genome of Saprolegnia ferax: Organization, gene content and nucleotide sequence. Mycologia 96:981-989.

Guo, L., Allen, K. S., Deiulio, G., Zhang, Y., Madeiras, A. M., Wick, R. L., and Ma, L.-J. 2016. A de novo-assembly based data analysis pipeline for plant obligate parasite metatranscriptomic studies. Front. Plant Sci. 7:925.

Haas, B. J., Papanicolaou, A., Yassour, M., Grabherr, M., Blood, P. D., Bowden, J., Couger, M. B., Eccles, D., Li, B., Lieber, M., Macmanes, M. D., Ott, M., Orvis, J., Pochet, N., Strozzi, F., Weeks, N., Westerman, R., William, T., Dewey, C. N., Henschel, R., Leduc, R. D., Friedman, N., and Regev, A. 2013. De novo transcript sequence reconstruction from RNA-seq using the Trinity platform for reference generation and analysis. Nat. Protoc. 8:1494-1512.

Hannon, G. 2010. FASTX Toolkit. Cold Spring Harbor Laboratory.

Hill, A. 2018. Agricultural Intensification in the Midwest: Impacts on Regional Surface Humidity. All Theses, Dissertations, and Other Capstone Projects 776. https://cornerstone.lib.mnsu.edu/etds/776

Holmes, G., Ojiambo, P. S., Hausbeck, M., Quesada-Ocampo, L. M., and Keinath, A. P. 2015. Resurgence of cucurbit downy mildew in the United States: A watershed event for research and extension. Plant Dis. 99: $428-441$.

Holt, C., and Yandell, M. 2011. MAKER2: An annotation pipeline and genome-database management tool for second-generation genome projects. BMC Bioinformatics 12:491.

Hudspeth, M., Shumard, D. S., Bradford, C., and Grossman, L. I. 1983. Organization of Achlya mtDNA: A population with two orientations and a large inverted repeat containing the rRNA genes. Proc. Natl. Acad. Sci. 80: $142-146$.

Ison, J. C., Rice, P. M., and Bleasby, A. J. 2011. EMBOSS Developer's Guide: Bioinformatics Programming. Cambridge University Press, Cambridge, United Kingdom.

Jiang, R. H. Y., Tripathy, S., Govers, F., and Tyler, B. M. 2008. RXLR effector reservoir in two Phytophthora species is dominated by a single rapidly evolving superfamily with more than 700 members. Proc. Natl. Acad. Sci. 105:4874-4879.

Kanehisa, M., Sato, Y., Kawashima, M., Furumichi, M., and Tanabe, M. 2016. KEGG as a reference resource for gene and protein annotation. Nucleic Acids Res. 44:D457-D462.

Kemen, E., Gardiner, A., Schultz-Larsen, T., Kemen, A. C., Balmuth, A. L., Robert-Seilaniantz, A., Bailey, K., Holub, E., Studholme, D. J., MacLean, D., and Jones, J. D. G. 2011. Gene gain and loss during dvolution of obligate parasitism in the white rust pathogen of Arabidopsis thaliana. PLoS Biol. 9:e1001094.

Klosterman, S. J., Anchieta, A., McRoberts, N., Koike, S. T., Subbarao, K. V., Voglmayr, H., Choi, Y.-J., Thines, M., and Martin, F. N. 2014. Coupling spore traps and quantitative PCR assays for detection of the downy mildew pathogens of spinach (Peronospora effusa) and beet (P. schachtii). Phytopathology 104:1349-1359.

Kong, X., Qin, W., Huang, X., Kong, F., Schoen, C. D., Feng, J., Wang, Z., and Zhang, H. 2016. Development and application of loop-mediated isothermal amplification (LAMP) for detection of Plasmopara viticola. Sci. Rep. 6: 28935.

Kumar, S., Jones, M., Koutsovoulos, G., Clarke, M., and Blaxter, M. 2013. Blobology: Exploring raw genome data for contaminants, symbionts and parasites using taxon-annotated GC-coverage plots. Front. Genet. 4:237.

Kunjeti, S. G., Anchieta, A., Martin, F. N., Choi, Y.-J., Thines, M., Michelmore, R. W., Koike, S. T., Tsuchida, C., Mahaffee, W., Subbarao, K. V., and Klosterman, S. J. 2016. Detection and quantification of Bremia lactucae by spore trapping and quantitative PCR. Phytopathology 106: 1426-1437.

Langmead, B., and Salzberg, S. L. 2012. Fast gapped-read alignment with Bowtie 2. Nat. Methods 9:357-359.

Levesque, C. A., Brouwer, H., Cano, L., Hamilton, J. P., Holt, C., Huitema, E., Raffaele, S., Robideau, G. P., Thines, M., Win, J., Zerillo, M. M., Beakes, G. W., Boore, J. L., Busam, D., Dumas, B., Ferriera, S., Fuerstenberg, S. I., Gachon, C. M. M., Gaulin, E., Govers, F., Grenville-Briggs, L., Horner, N., Hostetler, J., Jiang, R. H. Y., Johnson, J., Krajaejun, T., Lin, H. N., Meijer, 
H. J. G., Moore, B., Morris, P., Phuntmart, V., Puiu, D., Shetty, J., Stajich, J. E., Tripathy, S., Wawra, S., van West, P., Whitty, B. R., Coutinho, P. M., Henrissat, B., Martin, F., Thomas, P. D., Tyler, B. M., De Vries, R. P., Kamoun, S., Yandell, M., Tisserat, N., and Buell, C. R. 2010. Genome sequence of the necrotrophic plant pathogen Pythium ultimum reveals original pathogenicity mechanisms and effector repertoire. Genome Biol. 11:R73.

Lowe, T. M., and Eddy, S. R. 1997. tRNAscan-SE: A program for improved detection of transfer RNA genes in genomic sequence. Nucleic Acids Res. 25:955-964.

MacKinnon, D. 2004. USA Hops 2004 Statistical Report. Hops Growers of America, Yakima, WA.

Marçais, G., and Kingsford, C. 2011. A fast, lock-free approach for efficient parallel counting of occurrences of k-mers. Bioinformatics 27:764-770.

Martin, F. N., Bensasson, D., Tyler, B. M., and Boore, J. L. 2007. Mitochondrial genome sequences and comparative genomics of Phytophthora ramorum and $P$. sojae. Curr. Genet. 51:285-296.

Martin, M. 2012. Cutadapt removes adapter sequences from high-throughput sequencing reads. Bioinform. Action 17:10-12.

McNabb, S. A., Boyd, D. A., Belkhiri, A., Dick, M. W., and Klassen, G. R. 1987. An inverted repeat comprises more than three-quarters of the mitochondrial genome in two species of Pythium. Curr. Genet. 12:205-208.

Morgan, W., and Kamoun, S. 2007. RXLR effectors of plant pathogenic oomycetes. Curr. Opin. Microbiol. 10:332-338.

Moriya, Y., Itoh, M., Okuda, S., Yoshizawa, A. C., and Kanehisa, M. 2007. KAAS: An automatic genome annotation and pathway reconstruction server. Nucleic Acids Res. 35:W182-W185.

Natsume, S., Takagi, H., Shiraishi, A., Murata, J., Toyonaga, H., Patzak, J., Takagi, M., Yaegashi, H., Uemura, A., Mitsuoka, C., Yoshida, K., Krofta, K., Satake, H., Terauchi, R., and Ono, E. 2015. The draft genome of hop (Humulus lupulus), an essence for brewing. Plant Cell Physiol. 56:428-441.

Neve, R. A. 1991. Hops, 1st Ed. Chapman and Hall, London, United Kingdom.

O'Brien, M. A., Misner, I., and Lane, C. E. 2014. Mitochondrial genome sequences and comparative genomics of Achlya hypogyna and Thraustotheca clavata. J. Eukaryot. Microbiol. 61:146-154.

Ojiambo, P. S., Gent, D. H., Quesada-Ocampo, L. M., Hausbeck, M. K., and Holmes, G. J. 2015. Epidemiology and population biology of Pseudoperonospora cubensis: A model system for management of downy mildews. Annu. Rev. Phytopathol. 53:223-246.

Palmateer, A. J., Lopez, P., Seijo, T. E., and Peres, N. A. R. 2013. Severe outbreak of downy mildew caused by Plasmopara obducens on Impatiens walleriana in Florida. Plant Dis. 97:687.

Parra, G., Bradnam, K., and Korf, I. 2007. CEGMA: A pipeline to accurately annotate core genes in eukaryotic genomes. Bioinformatics 23: 1061-1067.

Petersen, T. N., Brunak, S., von Heijne, G., and Nielsen, H. 2011. SignalP 4.0: Discriminating signal peptides from transmembrane regions. Nat. Methods 8: 785-786.

Psifidi, A., Dovas, C., and Banos, G. 2011. Novel quantitative real-time LCR for the sensitive detection of SNP frequencies in pooled DNA: Method development, evaluation and application. PLoS One 6:e14560.

R Core Team. 2017. R: A Language and Environment for Statistical Computing. R Foundation for Statistical Computing, Vienna, Austria.

Rahman, A., Miles, T. D., Martin, F. N., and Quesada-Ocampo, L. M. 2017. Molecular approaches for biosurveillance of the cucurbit downy mildew pathogen, Pseudoperonospora cubensis. Can. J. Plant Pathol. 39:282-296.

Rivera, Y., Salgado-Salazar, C., Gulya, T. J., and Crouch, J. A. 2016. Newly emerged populations of Plasmopara halstedii infecting rudbeckia exhibit unique genotypic profiles and are distinct from sunflower-infecting strains. Phytopathology 106:752-761.

Roeckel-Drevet, P., Tourvieille, J., Drevet, J. R., Says-Lesage, V., Nicolas, P., and de Labrouhe, D. T. 1999. Development of a polymerase chain reaction diagnostic test for the detection of the biotrophic pathogen Plasmopara halstedii in sunflower. Can. J. Plant Pathol. 45:797-803.

Royle, D., and Kremheller, H. T. 1981. Downy mildew of the hop. Pages 395-419 in: The Downy Mildews. D. M. Spencer, ed. Academic Press, New York, New York.

Savory, E. A., Granke, L. L., Quesada-Ocampo, L. M., Varbanova, M., Hausbeck, M. K., and Day, B. 2011. The cucurbit downy mildew pathogen Pseudoperonospora cubensis. Mol. Plant Pathol. 12:217-226.

Savory, E. A., Zou, C., Adhikari, B. N., Hamilton, J. P., Buell, C. R., Shiu, S. H., and Day, B. 2012. Alternative splicing of a multi-drug transporter from Pseudoperonospora cubensis generates an RXLR effector protein that elicits a rapid cell death. PLoS One 7:e34701.
Schulze-Lefert, P., and Panstruga, R. 2011. A molecular evolutionary concept connecting nonhost resistance, pathogen host range, and pathogen speciation. Trends Plant Sci. 16:117-125.

Sharma, R., Xia, X., Cano, L. M., Evangelisti, E., Kemen, E., Judelson, H., Oome, S., Sambles, C., van den Hoogen, D. J., Kitner, M., Klein, J., Meijer, H. J., Spring, O., Win, J., Zipper, R., Bode, H. B., Govers, F., Kamoun, S., Schornack, S., Studholme, D. J., Van den Ackerveken, G., and Thines, M. 2015. Genome analyses of the sunflower pathogen Plasmopara halstedii provide insights into effector evolution in downy mildews and Phytophthora. BMC Genomics 16:741.

Simão, F. A., Waterhouse, R. M., Ioannidis, P., Kriventseva, E. V., and Zdobnov, E. M. 2015. BUSCO: Assessing genome assembly and annotation completeness with single-copy orthologs. Bioinformatics 31: 3210-3212.

Simpson, J. T., Wong, K., Jackman, S. D., Schein, J. E., Jones, S. J., and Birol, I. 2009. ABySS: A parallel assembler for short read sequence data. Genome Res. 19:1117-1123.

Skotland, C., and Johnson, D. A. 1983. Control of downy mildew of hops. Plant Dis. 67:1183-1186.

Studholme, D. J., Glover, R. H., and Boonham, N. 2011. Application of highthroughput DNA sequencing in phytopathology. Annu. Rev. Phytopathol. 49:87-105.

Stukenbrock, E. H. 2013. Evolution, selection and isolation: A genomic view of speciation in fungal plant pathogens. New Phytol. 199:895-907.

Stukenbrock, E. H., Jørgensen, F. G., Zala, M., Hansen, T. T., McDonald, B. A., and Schierup, M. H. 2010. Whole-genome and chromosome evolution associated with host adaptation and speciation of the wheat pathogen Mycosphaerella graminicola. PLoS Genet. 6:e1001189.

Summers, C. F., Gulliford, C. M., Carlson, C. H., Lillis, J. A., Carlson, M. O., Cadle-Davidson, L., Gent, D. H., and Smart, C. D. 2015. Identification of genetic variation between obligate plant pathogens Pseudoperonospora cubensis and $P$. humuli using RNA sequencing and Genotyping-BySequencing. PLoS One 10:e0143665.

The UniProt Consortium. 2016. UniProt: The universal protein knowledgebase. Nucleic Acids Res. 45:D158-D169.

The UniProt Consortium. 2018. UniProt: The universal protein knowledgebase. Nucleic Acids Res. 46:2699

Thines, M. 2014. Phylogeny and evolution of plant pathogenic oomycetes - a global overview. Eur. J. Plant Pathol. 138:431-447.

Thines, M., and Choi, Y.-J. 2016. Evolution, diversity, and taxonomy of the Peronosporaceae, with focus on the genus Peronospora. Phytopathology 106:6-18.

Tian, M. Y., Win, J., Savory, E., Burkhardt, A., Held, M., Brandizzi, F., and Day, B. 2011. 454 Genome sequencing of Pseudoperonospora cubensis reveals effector proteins with a QXLR translocation Motif. MPMI 24:543-553.

Voglmayr, H., and Greilhuber, J. 1998. Genome size determination in Peronosporales (Oomycota) by Feulgen image analysis. Fungal Genet. Biol. 25:181-195.

Vurture, G. W., Sedlazeck, F. J., Nattestad, M., Underwood, C. J., Fang, H., Gurtowski, J., and Schatz, M. C. 2017. GenomeScope: Fast reference-free genome profiling from short reads. Bioinformatics 33: 2202-2204.

Wallace, E. C., and Quesada-Ocampo, L. M. 2017. Analysis of microsatellites from the transcriptome of downy mildew pathogens and their application for characterization of Pseudoperonospora populations. PeerJ 5:e3266.

Wickham, H. 2009. Elegant Graphics for Data Analysis. Springer-Verlag, New York, New York.

Win, J., Krasileva, K. V., Kamoun, S., Shirasu, K., Staskawicz, B. J., and Banfield, M. J. 2012. Sequence divergent RXLR effectors share a structural fold conserved across plant pathogenic oomycete species. PLoS Pathog 8: e1002400.

Withers, S., Gongora-Castillo, E., Gent, D., Thomas, A., Ojiambo, P. S., and Quesada-Ocampo, L. M. 2016. Using next-generation sequencing to develop molecular diagnostics for Pseudoperonospora cubensis, the cucurbit downy mildew pathogen. Phytopathology 106:1105-1116.

Wyenandt, C. A., Simon, J. E., Pyne, R. M., Homa, K., McGrath, M. T., Zhang, S., Raid, R. N., Ma, L.-J., Wick, R., Guo, L., and Madeiras, A. 2015. Basil downy mildew (Peronospora belbahrii): Discoveries and challenges relative to its control. Phytopathology 105:885-894.

Yin, L., An, Y. H., Qu, J. J., Li, X. L., Zhang, Y. L., Dry, I., Wu, H. J., and Lu, J. 2017. Genome sequence of Plasmopara viticola and insight into the pathogenic mechanism. Sci. Rep. 7:46553. 